\title{
XVIII.
}

\section{Ueber den Pulsus alternans.}

Eine klinisch-experimentelle Studie.

Yon

Dr. Julius Schreiber,

Assistenz-Arzt an der medicinischen Universitätsklinik Königsberg (i. Pr.).

Im Laufe der letzten drei Semester hatte ich in der Klinik des Herrn Prof. Nauny n Gelegenheit, in zwölf Krankheitsfällen den Pulsus alternans oder bigeminus zum Theil eine recht lange Zeit hindurch zu beobachten. Gleich der erste Fall, bei dem diese Pulsart hervortrat, gestaltete sich in mannigfacher Weise so interessant, dass er mir Veranlassung wurde der Frage nach seiner Entstehung etwas näher nachzuforschen. Im Nachstehenden habe ich es versucht, meine klinischen Beobachtungen und die zu ihrer Unterstiitzung gemachten Experimente, so weit sie der Beantwortung dieser Frage zu dienen im Stande waren, zusammenzustellen.

Ich nehme hierbei Gelegenheit Herrn Professor $\mathrm{Naunyn}$ für seine bereitwilligste Förderung meiner Arbeit meinen besten Dank abzustatten.

In derselben werde ich mich ausschliesslich auf die Erklärung der vorgenannten pathologischen Pulsphänomene beschränken und auf einige wenige vielleicht sonst wünschenswerthe Erklärungen der Zeichnungen in einer zweiten Untersuchungsreihe zurückkommen.

Die beigegebenen Curvenzeichnungen sind zum Theil mit dem Marey'schen Sphygmographen, zum Theil mit dem Marey'schen Cardiographen gewonnen; welcher von den beiden Apparaten in Anwendung gezogen, werde ich an den einzelnen Zeichnungen durch die Beisetzung des Buchstaben C. oder S. vermerken.

Ueber die Art der Anwendung des Marey'schen Cardiographen zunächst für meine Untersuchungen sowie uiber die Berechtigung, 
die mit diesem Instrumente gewonnenen Curven den sphygmographischen gleichzusetzen, auch dariber werde ich an einer anderen Stelle ausführlich eingehen. Ich unterlasse hier die bezüglichen Auseinandersetzungen, um zu weitgehende Erörterungen zu meiden, und weil die in den fraglichen Pulsbildern bestehenden Difterenzen, wenn sie überhaupt vorbanden, für die von mir behandelte Frage von absolut untergeordneter Natur sind.

In der ersten meiner Beobachtungen handelte es sich um ein 16 jähriges Mädchen, A. N., das bis ein Vierteljahr vor ihrer jetzigen Erkrankung vollständig gesund gewesen sein will. Um diese Zeit erkrankte sie an einem Unterleibstyphus, weswegen sie 6 Wochen auf unserer Klinik behandelt wurde. Kaum entlassen erkrankte sie 8 Tage später von Neuem und zwar unter den Erscheinungen einer ziemlich heftigen Pericarditis. Nachdem dieses Leiden, an dem ich sie selbst zu behandeln Gelegenheit hatte, nach mehreren Wochen sich fast vollständig gebessert hatte, begann schnell hinterher bei der Kranken sich dauerndes Herzklopfen einzustellen, das häufig mit grosser Athemnoth und Stichen in der Herzgegend verbunden war. Da diese Beschwerden sich allmählich steigerten und andere schwere Erscheinungen hinzutraten, wurde ibre abermalige Aufnahme in die med. Klinik am 26. Februar v. J. veranlasst.

Die Patientin wird in die Klinik unter den Erscheinungen höchster Dyspnoe aufgenommen; zu Bett gebracht vermag sie nur in aufrecht sitzender Stellung die angeblich grossen Qualen von Lufthunger mühevoll zu ertragen. Die Respirationsfrequenz ist sehr vermehrt (50 pr. Minute), dabei oberfächlich und im rein costalen Typus. Die Veränderung dieser Lage in irgend welcher Richtung steigert die genannten Beschwerden soweit überhaupt noch möglich. Geringes Oedema supra malleolos. Temperatur dem Gefühl nach nicht erhöht. Puls $130 \mathrm{pr}$. Minute, unregelmässig, zeitweise aussetzend, sehr klein und weich, mässig celer. Gesicht lebhaft geröthet und stark cyanotisch, letzteres desgleichen bezïglich der Lippen. Halsvenen wenig geschwellt, nicht pulsirend, schwache Pulsation der Carotiden. Die Percussion ergibt eine Vergrösserung ider Herzdämpfung nach links sowie nach rechts. Die Palpation lässt einen kräftigen Herzchoc erkennen, der eigenthümlich gegensätzlich dem sehr kleinen und weichen Pulse scheint. Dabei ist die Herzaction uiber allen Punkten höchst unregelmässig und an der gewöhnlichen Stelle der nicht ganz abgrenzbaren Spitze hören sich die etwas dumpf 
und verschleiert scheinenden Töne im Rhythmus etwa eines kurzen beginnenden Wirbels an. Folgendes Versschema würde ungefähr die Folge der vorgenannten Auscultationsphänomene graphisch darstellen :

Zeitweise tritt an der Spitze ein Geräusch hervor, über dessen Zugehörigkeit zur systolischen oder diastolischen Herzphase man zur Zeit nichts Bestimmtes auszusagen vermag.

Ord.: Inf. digit. $1,0 / 200,02$ stdl.

27. 2. Die Action des Herzens ist beute noch nahezu dieselbe wie Tags vorher. Die einzelnen Herzschläge scheinen nicht gleich. Der Puls fühlt sich fast dicrotisch an und scheint der dicrotische Nachschlag das eine Mal etwas spät zu kommen, das andere Mal fast ganz zu fehlen. Die Anzahl derselben beträgt 45 pr. Minute (Ord. id.).

29. 2. Die Herzaction ist noch immer beschleunigt. Bei der Palpation scheint es als ob zwei kurze Erhebungen hintereinander folgen und dann eine relativ grössere Pause zwischen sich lassen, etwa folgender Darstellung entsprechend:

wobei die Punkte die relativ verlängerte Herzpause andeuten sollen. Dasselbe ergibt die Auscultation, bei der gleichzeitig ein deutliches systolisches Geräusch an der Spitze vernommen wird, das sowohl beim ersten wie beim zweiten Spitzenstosse auftritt und sich auch nach dem unteren Theile des Sternum fortpflanzt. Puls klein und von früherer Beschaffenheit, etwa 100.

1. 3. Die orthopnoïschen Beschwerden haben etwas nachgelassen, desgleichen die Schmerzen in der Herzgegend. Die eigenthümliche Doppelschlägigkeit des Herzens besteht auch heute noch und auf je zwei Erhebungen desselben fühlt man einen relativ kräftigen Puls, der scheinbar dicrotisch ist. Bei der Palpation der Herzgegend, sobald man die volle flache Hand über die Gegend zwischen Spitzenstoss and unteren Theil des Sternums legt, fühlt man, wie bald die Gegend der Spitze, bald die des Sternums mächtiger hervortritt. Dem ersteren Choc entspricht der kräftige Puls und so scheint es, als ob man durch Palpation und Auscultation am Herzen 102 Erhebungen pr. Minute habe, denen 50 dicrotische Pulse an der Radialis und an sämmtlichen übrigen der Palpation zugänglichen Arterien entsprechen. Bei genauerer Prüfung findet man jedoch das Verhältniss so, dass auf den kräftigeren ersten Herzschlag der volle Radialpuls, auf den zweiten schwächeren die scheinbar dicrotische Erhebung folgt. 
2. 3. Die Erscheinungen am Herzen sind fast ganz dieselben. Der zweite Pulmonalton erscheint heut exquisit klappend und ist als solcher schon durch die Palpation wahrzunehmen. Dabei kann durch die Auscultation wie durch die Palpation ein Unterschied in der Stärke zweier aufeinander folgender diastolischer Pulmonaltöne wahrgenommen werden der Art, dass der mehr klappende auf den vollen Radialpuls, der weniger klappende auf die scheinbare Dikrotie folgt. Der kräftigere Puls entspricht scheinbar der Action des linken Herztheils, die zweite kleinere Welle der des rechten; doch ist ausdrücklich hervorzuheben, dass bei gesonderter Palpation beider Herzgegenden man die Action in der linken stets deutlich und ron fast. gleicher Stärke fühlt, während die Contractionswelle nur das eine Mal sich auch mit besonderer Deutlichkeit auf die rechte auszudehnen scheint.

6. 3. Der Zustand der Patientin am heutigen Tage gestattet die Aufnahme eines ausführlichen Status. Derselbe zeigt in der sechszehnjährigen Kranken ein für ihr Alter gut entwickeltes Mädchen, mit dünner, aber fester Musculatur, mit gutem Knochenbau und geringem Pann. adip.; auf der blassen, namentlich auf der Brust durchscheinenden Haut keine nennenswerthe Veränderung zeigend; ihre Temperatur nicht erhöht, keine erhebliche Dyspnoe, keine Oedeme. Puls regelmässig, etwas frequent, klein, von mässiger Resistenz und in seiner Höhe rhythmisch der Art wechselnd, dass einer höheren Welle eine niedere folgt, von denen jede einer besonderen Ventrikelcontraction entspricht. Pt. liegt in activer Rückenlage mit etwas erhöhtem Oberkörper, ist dabei heute bereits im Stande', diese Lage mit jeder anderen ohne Beschwerden zu vertauschen. Subjective Klagen sind zur Zeit nicht mehr vorhanden. Wangen sehr eyanotisch, desgleichen die Lippen, in geringerem Grade die Zunge. Die Cyanose tritt um so deutlicher hervor, als die Wangen und die sichtbaren Schleimhäute des Gesichts sehr anämisch sind. Hals von gewöhnlicher Länge mit selbst bei Hustenstössen nur undeutlich hervortretenden Venen, dagegen mit deutlicheren Pulsationen der arteriellen Gefässe daselbst. Thorax etwas inspiratorisch, sonst aber gut gebaut, im Axillartheil der linken Seite vielleicht etwas mehr ektatisch erscheinend. Mit Uebergehung der Details der im wesentlichen normalen Auscultations- und Percussionsverhältnisse der Lungen beginnt links auf der dritten Rippe eine Dämpfung, die sich nach abwärts bis in die gewöhnliche Gegend des balbmondförmigen Raumes erstreckt; sie reicht nach rechts bis an den rechten Sternalrand, nach links geht sie in einem zur linken 
Schulter ziemlich stark convexen Bogen zur Stelle des iSpitzenstosses. Letzterer ist im 5. Intercostalraum fast 1 " nach links von der linken Mammillarlinie sehr deutlich sicht- und als verbreitert and hebend fühlbar. Sobald man die volle Hand auf den unteren Theil der Herzgegend legt, fühlt man deutlich, dass jeder stärkeren Erhebung: und Senkung des Herzens eine etwas schwächere folgt. Bei der Auscultation hört man an der Spitze ein systolisches Geräusch neben einem systolischen und diastolischen Ton. Ersteres zeigt in Bezng auf seine Stärke einen gleichen Wechsel wie die Action selbst. Dabei scheint es ausserdem bei der Inspiration etwas an Deutlichkeit zu gewinnen. Dieselben Ergebnisse der Auscultation am unteren Theil des Sternum. An der Aorta und Pulmonalis kein Geräusch zu constatiren; ïber letzterer der zweite Ton klappend. Das Verhältniss zweier Pulserhebungen bezïglich ihrer Höhe an der Radialis Carotis und Femoralis sowie der Wechsel im zweiten klappenden Pulmonalton sind dieselben wie bereits oben erwähnt. Abdomen wenig aufgetrieben.

Leber der Percussion nach in der Lin. mamm. 2 Finger breit den Rippensaum iuberragend. Lebergegend auf Druck nicht besonders schmerzhaft.

Milz nicht vergrössert. Urin spärlich, saturirt, spec. Gew. 1,020, Spuren von Eiweiss.

Es sei nur noch bemerkt, dass die Kranke am 22. April im Wesentlichen frei von Beschwerden aus der klinischen Behandlung entlassen" worden ist. Ich behielt sie von der Zeit ab in weiterer Beobachtung und habe sie in Zwischenräumen von $3-5$ Wochen, jedesmal mehrere Tage hintereinander sehen und untersuchen können. Ich werde auf die Ergebnisse dieser Untersuchung noch einmal weiter unten zurückkommen, weil sich bei diesem Krankheitsfall schliesslich noch andere sehr interessante und, soweit mir bekannt, bisher noch nicht beobachtete Erscheinungen herausstellten.

Zuvor seien einige während ihrer ersten Zeit in der Klinik von der Kranken sphygmographisch gewonnene Curven kurz besprochen.

No. 1.

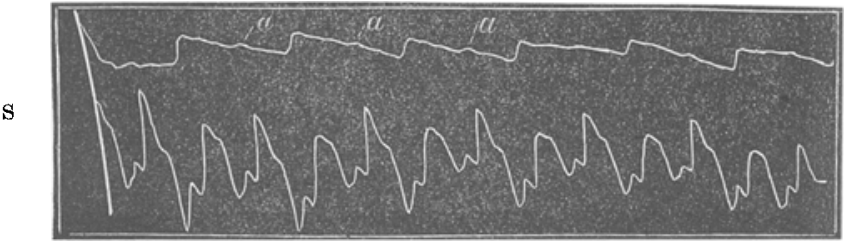


Aus dem vorangesetzten Status erfubren wir, dass in den ersten Tagen es schien, als ob zweien Herzstössen nur ein Radialpuls folgte-

In der That bestätigt die vorgestellte Curve das Ergebniss der Palpation. Nur bei genanerer Betrachtung der oberen Curve (Radialis) sieht man leichte Andeutungen einer kleineren Pulswelle ( $a$ a die 'zunächst bei flüchtiger Beobachtung für Dicrotie angesprochen werden könnte. Die hinterher gewonnene (untere) Herzcurve von der Stelle der fühlbaren Spitze gibt ganz zufällig auch das vorgenannte Verhältniss des breiteren und enger begrenzten Herzchoes in den spitzwinkligen und breiteren Curvenzipfeln zu den volleren und den scheinbar fehlenden Pulsen zu erkennen. Dass diese trotz der verschiedenen Zeit gefundene Curve zufällig die richtige, werde ich weiter unten an solchen, die mit Hülfe zweier Cardiographen am Herzen und an der Radialis synchron gezeichnet worden, demonstriren können. Mit dem Abnehmen der Beschwerden wird die früher undeutliche zweite Erhebung an der Radiahis zu einem deutlichen, auf den zweiten kürzeren aber breiteren Herzchoc fallenden, kleineren selbstständigen Pulse bei $a$ in No. 2.

No. 2.

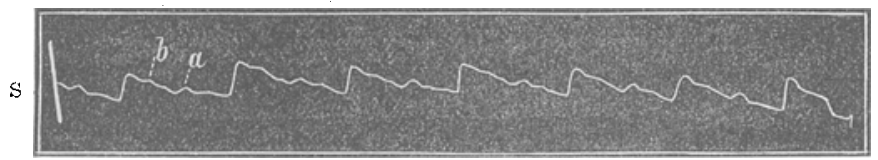

No. 3.

S

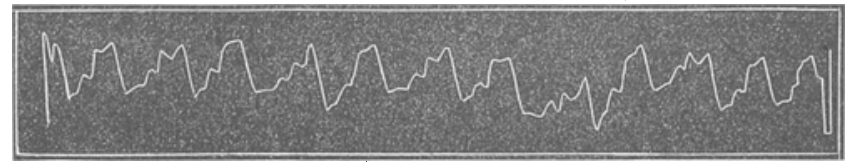

Die Curve ist rom unteren Theile des Sternums genommen.

Wir hatten es somit mit einem regelmässig alternirenden Pulse zu thun, der der Zeichnung nach zunächst von einem stärkeren und schwächeren Herzstoss abzuhängen schien. Da trat bei der Kranken ein deutlich sicht- und fühlbarer Puls am Bulbus venae jugularis

No. 4.

S

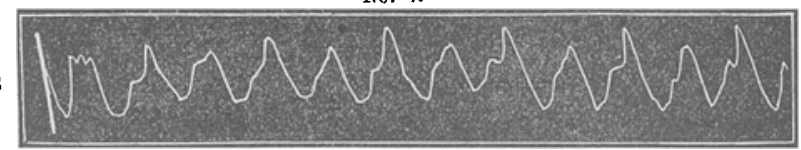
auf und gleichzeitig wurde die an der Radialis ${ }^{1}$ ) gefuhlte kleinere zweite Erhebung wieder undeutlich und für Stunden am Tage sogar

1) Ich habe gleichzeitig von der Carotis, Cubitalis und Femoralis Pulse genommen, die sich alle wie die von der Radialis verhielten, daher seien hier wie auch weiterhin die Veränderungen am Radialpuls als allgemeiner Ausdruck der im Arteriensystem bestandenen Veränderungen gebraucht. 
ganz fehlend; im Gegensatz hierzu erschien der Bulbuspuls sehr deutlich und was am auffallendsten war, noch einmal so bäufig wie der an der Radialis, bezw. gleich häufig mit der Zahl der Herzstösse.

Um Raum zu ersparen, will ich diesen Puls hier nur allein geben. Ein Vergleich mit den ersten beiden beleuchtet das Gesagte zur Genuige. Dass es sich hierbei etwa um eine Verwechselung mit einem Carotis- oder Subclavialpulse handelte, darf wohl kaum erörtert werden. Die anadikrotische Beschaffenheit des Venenpulses verräth uns zugleich, welche andere Störung in der Mechanik des Herzens zu der frïheren sich hinzugesellt hatte, wie sie ausserdem ihre Aehnlichkeit mit den vom Herzen selbst gewonnenen Curven mit ihren abwechselnden Spitzen und mehr stumpfen Curvengipfeln deutlich erkennen lässt. Nach diesem Befunde war zu seiner Erklärung der Gedanke an eine mögliche doppelte resp. gesonderte Contraction des rechten Ventrikels vielleicht nicht von der Hand zu weisen und hiervon ausgehend versuchte ich von der äussersten linken Begrenzung des Herzens sowie vom unteren Theile des Sternums Herzstosscurven zu gewinnen.

Die Curven

No. 5 u. 6 geben die Herzstosscur- $\mathrm{s}$ ven, die erste vom unteren Theil des Sternums, die zweite von der äussersten linken Begrenzung des Herzens. Hier- $s$ nach contrahirte sich dasselbe als Ganzes gleich häufig - soweit man aus der Zeichnung ${ }^{1)}$ schliessen durfte, $\mathrm{s}$ während die so-

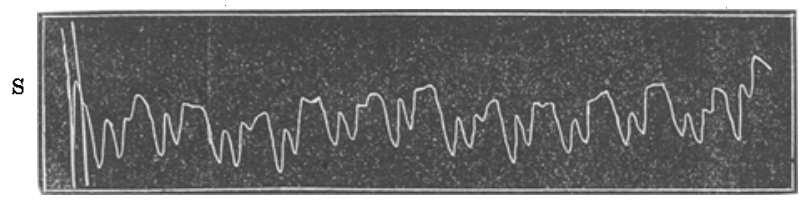

Unterer Theil des Sternums. No. 6.

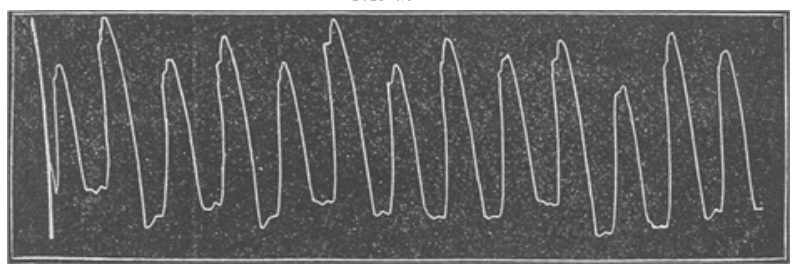

Spitzenstoss 25. 3. 76. A. Neuminn Schr.

No. 7.

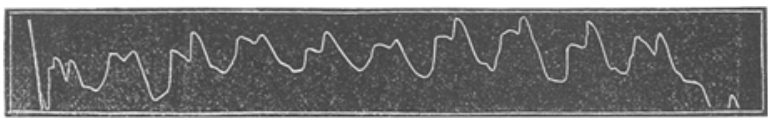
fort hinterher gewonnenen Curven No. 7 vom Venenbulbus und No. 8 von der Radialis das vorgenannte Verhältniss darboten.

1) Auf die ausführliche Deutung der auffallend starken Dicrotieen der obersten Curve werde ich ausführlich an einer anderen stelle einzugehen haben. 
No. 8.

Doch ich will

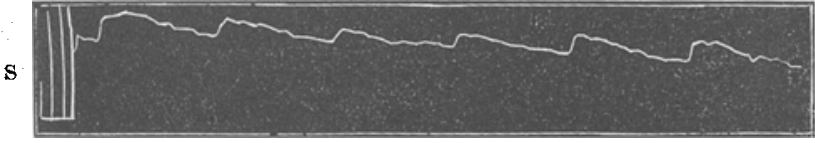
die Erörterung der Frage, ob man hieraus eine Radialis 28, 3, 76. A. Neumann Schr. gesonderte Action des rechten Ventrikels, ftir die ja der mit den Contractionen des Herzens gleich häufige Venenpuls zu sprechen schien - anzunehmen berechtigt war, zunächst fallen lassen, um der besseren Uebersicht wegen die weiteren Veränderungen am Pulse zu beendigen. Derselbe gestaltete sich nun in Folge derart, dass bei ziemlich gleichbleibender Herzstosscurve der fruher annähernd gleiche Bulbuspuls deutlich alternirend zu werden begann. Mit dem Auftreten dieser Veränderung erschien an der Radialis die früher häufig fehlende Dikrotie um so deutlicher und um so constanter als zweite kleine selbstständige Pulswelle, je alternirender der erste war.

No. 9.

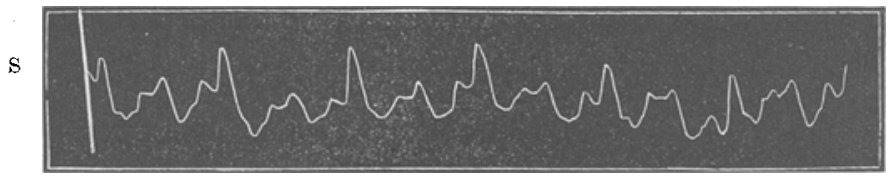

No. 10.

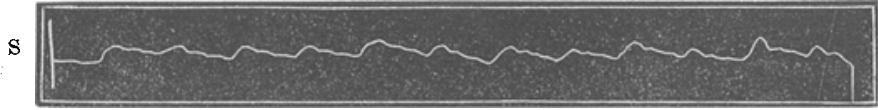

Eine Woche ungefähr hielt der Venenpuls an; nach seinem Verschwinden blieb der Radialpuls in der nachstehenden Weise, die Herzaction in der vorherigen Zeichnung bestehen.

Diese Curve stammt

s

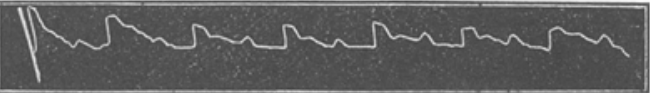
vom Tage der Entlassung der Kranken aus der Klinik. Ich habe um dem Verlauf der Veränderungen mehr im Zusammenhang geben zu können, es vermieden, die einzelnen Tagesnotizen hier zu detailliren und füge daher nachträglich nur noch zur Beurtheilung der Erscheinungen hinzu, dass die Kranke in den ersten vier Tagen ihres Aufenthaltes in der Klinik 2,0 Digitalis als Infus und hierauf in den nächsten 14 Tagen eine Mixtur von

Tinct. ferri pomat. 15,0

" digitalis 7,5

3 mal täglich 20 Tropfen

verbraucht hat. Wälurend der nächsten 3 Monate, in denen sich die 
Kranke unter dem Gebrauch von Blaud'schen Pillen durchaus wohl fulhlte, sah ich sie sehr häufig und constatirte an ihr jedes. Mal den exquisitesten Pulsus alternans. Ganz vortibergehend traten im Monat Juli wieder Athembeschwerden und Herzklopfen auf, die nach einem mehrtägigen Gebrauch obiger Mixtur nachliessen. So oft die Kranke auch nach dieser Zeit bei mir erschien, fand ich den Pulsus alternans. Im Verlaufe der häufigen Untersuchungen ergab sich ein grosser Wechsel in den Auscultationsphänomenen am Herzen: bald war ein leises systolisches Geräusch an der Spitze nachweisbar, bald fehlte dasselbe, während der zweite Pulmonalton stets klappend blieb. Mit diesem Befunde habe ich die Kranke noch vor wenigen Tagen gesehen und nachstehende Curve mit dem Cardiographen aufgenommen.

No. 12.

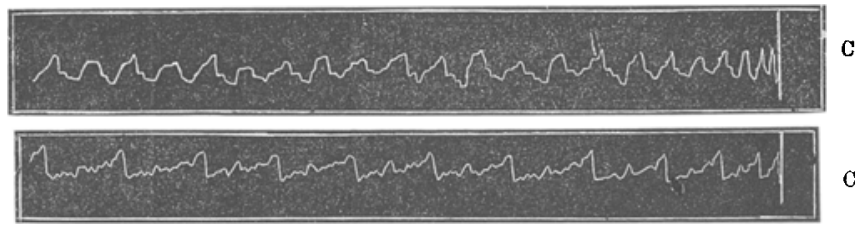

Die obere Herzcurve ${ }^{1}$ ) zeigt wiederum mebr spitz- und mehr stumpfwinklige Curvengipfel in regelmässiger Aufeinanderfolge; da beide Zeichnungen gleichzeitig gefertigt sind, die Federn beider Tambours senkrecht übereinander standen, so ist es auch gestattet die übereinanderliegenden Puls- und Herzzeichnungen in der Zeit aufeinander zu beziehen. Diese Relation bestatigt mit aller Deutlichkeit das von mir aus der ersten Zeit abgeleitete Verhältniss des enger begrenzten und des weiteren Herzstosses zum dentlich und zum weniger deutlich fühlbaren Radialpulse.

Dieser Krankheitsfall zeigt uns unter Anderem somit einen nun fast ein Jahr hindurch bestehenden von etwaiger Digitaliseinwirkung unbeeinflussten Pulsus alternans bei einem übrigens relativ sehr gutem Befinden der mit dem weiter unten im Zusammenhang zu besprechenden Vitium cordis behafteten Person. Bei der Gelegenheit werde ich auch auf die möglichen Ursachen obiger Pulsveränderung eingehen, nachdem ich zuvor die folgenden Krankheitsfälle in ihren Erscheinungsweisen detaillirt habe.

1) Die Herzcurve ist mit einer hier nachgearbeiteten mangelhaften Mareyschen Coquille gewonnen, daher die Zeichnung weniger exact als die untere. Diese wie die folgende mit dem Cardiographen gezeichneten Curven sind in umgekehrter Richtung wie die sphygmographischen zu lesen. 
Es handelt sich in dem zweiten Falle um eine 34 jährige Frau, W. G., die bis vor 3 Jahren vollständig gesund gewesen sein will. In der genannten Zeit fiel sie bei einem Sprung uber einen Graben, wobei sie sich angeblich das Brustschild verletzte. In der weiteren Folge soll sich im Verlaufe von wenigen Wochen eine Geschwulst in der rechten Seite des Leibes gebildet haben und der Leib und die Füsse schwollen an. Letzteres nahm bald unter dem Grebrauch von Medicin ab; aber Herzklopfen und Stiche auf der Brust blieben seit der Zeit constant und wurden bei der mässigsten Körperanstrengung stets heftiger. An Rheumatismus hat die Kranke angeblich nie gelitten.

Mittelgrosse Frau mit ziemlich gutem Knochenbau und auch sonstigem ziemlich gutem Ernährungszustand; mässige Cyanose des Gesichts, der Finger, der Zehen und des Fussruckens; an den Unterschenkeln sehr stark ektatische Venen. Hautfarbe sonst blass, Temperatur der Haut nicht erhöht, keine Dyspnoe, geringes Oedem der unteren Extremitäten. Die Kranke geht meist umher, nimmt bei der Untersuchung eine mehr sitzende Stellung ein, bevorzugt die rechte Seitenlage, weil bei der entgegengesetzten angeblich sofort Schmerzen und Stiche auftreten. Die subjectiven Klagen beziehen sich auf starke Schwellung des Leibes und Herzklopfen und dadurch bedingte Schwäche und Aengstlichkeit. Etwas leidender Gesichtsausdruck, anämische Conjunctival- und Lippenschleimhaut. Am langen Halse treten die Jugularvenen als blaue Stränge, der Bulbus venae jugularis besonders bei Hustenstössen als etwa wallnussgrosser Tumor hervor; Vene und Bulbus pulsiren in noch näher zu bezeichnender Weise; sonst am Halse nichts Abnormes zu verzeichnen. - Thorax in den seitlichen Partieen flach, in den mittleren hervortretend erinnert in vieler Beziehung an den paralytischen. Percussion und Auscultation der Lungen ergeben nur die Zeichen eines höheren Standes der unteren Grenzen derselben. Herzdämpfung beginnt auf der 3. Rippe 1 Zoll links vom Sternum, geht in etwas nach unten schräger linie uiber dieselbe hinweg, ist auf der nächstfolgenden Rippe bis fast 1 Zoll jenseits des rechten Sternalrandes zu verfolgen und hält sich auf der 5. und 6. um etwa Fingerbreite auf dieser Seite des Brustbeines. Nach links fällt die Grenze in einer etwas mehr steilen Linie, die von der oberen bis zur Stelle des Spitzenstosses geht, allmählich ab, letzterer ist im 6. Intercostalraume in einer Ausdehnung von etwa 2-3 Fingerkuppen in der linken Mammillarlinie sicht- und fuhlbar; von hier aus sieht man wellenförmig sich nach der oberen Grenze hinziehende rhythmische 
Contractionen; bei der Palpation tritt an der Spitze ein sehr langgezogenes Frèmissement, deutlich der diastolischen Phase angehörig hervor, dasselbe hält fast eine Secunde lang an und ihm folgen eine normal lange systolische Erschitterung mit einer kurzen von einem Frémissement begleiteten diastolischen Einsenkung, auf diese wiederum schnell hinterher eine zweite kurze Systole, worauf abermals mit jener vorher genannten langen Diastole dieses eigenthümliche rhythmische Spiel sich wiederholt. Vergleichen wir mit dieser Herzaction den Puls an der Radialis, sowie am Bulbus venae jugularis, so ergibt sich folgendes Verhältniss derselben zu einander: Der erstere ist sehr klein, mässig resistent, scheinbar regelmässig und deutlich dikrotisch, letzterer kräftig, hoch und von einer noch einmal so grossen Häufigkeit als der an der Radialis; aber schon palpatorisch erkennt man, dass die Venenpulswellen in ihren Höhen rhythmisch wechseln. Mit der Herzaction verglichen folgt der eigentliche Radialpuls der der langen Diastole hinterhergehenden systolischen Erschütterung des Herzens, wobei gleichzeitig auffällt, dass die vermeintliche dikrotische Erhebung genau der zweiten Systole des Herzens entspricht. Diese zweite kleinere Pulserhebung ist übrigens zuweilen deutlich, zuweilen aber nur kaum durch das Gefühl zu erkennen. Die Anzahl der einzelnen Erhebungen des Herzens betragen in der Minute $\mathbf{7 2}$, gleich häufig pulsirt der Bulbus venae jugularis, während der Radialpuls als dikrotischer aufgefasst genau halb so häufig erscheint; indess mit Anerkennung dieser secundären kleineren Welle als selbstständige pulsatorische Erhebung würde der Radialpuls bezüglich seiner Schläge mit denen an den Halsvenen und am Herzen gleich stehen. Bei der. Auscultation hört man an der Spitze zwei systolische kurze Geräusche, zwischen ihnen ein unbestimmtes kurzes, dumpfes diastolisches Auscultationsphänomen, beiden aber folgend ein lang gezogenes sausendes, sehr lautes diastolisches Geräusch, welches hier am stärksten und fast ausschliesslich zu hören ist. Am unteren Theil des Sternum zwei kurze systolische Geräusche, denen ein leises diastolisches Sausen folgt. Ueber der Pulmonalis in der Systole einen unreinen, vielleicht von einem kurzen systolischen Geräusch begleiteten Ton sowie einen deutlich klappenden diastolischen; beide Töne erscheinen schwächer mit und nach der zweiten systolischen Erhebung des Herzens. Fast dasselbe hört man über der Aorta, nur ist der zweite Ton nicht klappend und das systolische Geräusch etwas deutlicher, dasselbe wiederum wie hier und abermals schwächer über der Carotis zu hören. Es ist nachträglich noch hervorzuheben, dass die beiden systolischen 
Erhebungen an der Herzspitze von annähernd gleicher Intensität zu sein scheinen, wohingegen iuber dem unteren Theil des Sternums und uberhaupt nach rechts hin der erste systolische Stoss nicht nur ganz erheblich vor dem zweiten prävalirt, sondern dass man bei gleichzeitiger Palpation der ganzen Herzgegend den Eindruck bekommt, als ob in der ersten Systole eine gleichmässige Erhebung derselben . stattfände, während in der zweiten gewissermassen das Herz nach rechts hinübergeschleudert würde, derart, dass die grösste Intensität dieser Kraftäusserung mehr am Orte des scheinbaren Ursprunges, d. b. nach links hin liege.

Abdomen auffallend stark gewölbt zeigt eine grösste Circumferenz von $130 \mathrm{Ctm}$, die Abdominalwandungen sind gespannt, auf Druck nirgends besonders schmerzhaft, mit den gewöhnlichen Zeichen eines freien Flïssigkeitsergusses in demselben; infolge letzteres wird es zunächst unmöglich die untere Lebergrenze zu bestimmen, deren obere am oberen Rande der funften Rippe in der Linea mammillaris gelegen ist. Milzdämpfung mit Sicherheit nicht nachweisbar. Urin spärlich, saturirt, kein Eiweiss.

Mit Uebergehung der dazwischen liegenden Journalnotizen sei erwähnt, dass die Kranke am 5. Juni die Klinik zu verlassen wïnschte; bis dahin waren die Erscheinungen am Herzen für Stunden bald so, dass zwei Herzstössen ein Radialpuls beziehungsweise ein grosser und ein kleiner folgte, während am Bulbus venae jugularis zwei annähernd gleich starke Erhebungen sich zeigten, bald der Jugularvenenpuls weniger ausgeprägt oder gar nicht vorhanden war und dann der Radialpuls voller und deutlicher alternirend erschien, bald auch eine andere nicht näher zu bestimmende Unregelmässigkeit in der Herzaction und in den Pulsen sich zeigte. Da der Ascites durch keine der angewandten diuretischen und diaphoretischen Medicationen zu heben oder zu mildern war, so wurde an dem genannten Tage die Punctio abdominis ausgeführt. Nachdem auf diesem Wege 12000 C.-Ctm. einer übrigens reinen Ascitesflüssigkeit entleert worden waren, kam ein mässiger Lebertumor zum Vorschein, der fast bis zum Nabel und nach links bis fast zur verlängerten Mammillarlinie reichte; die Leber fühlte sich resistent und an ihrem Rande abgestumpft an, auf Druck wenig schmerzhaft. Durch die Entleerung fiel die Banchwand so mächtig ein, dass man zwischen dem oberen Lebertheil und dem Proc. xiphoides sterni ziemlich tief mit den Fingerkuppen eindringen und von hier aus den tiber dem Zwerchfell gelegenen Theil des Herzens mit ausserordentlicher Deutlichkeit fühlen konnte. Man erkannte hierbei, wie die erste systo- 
lische Erschütterung diesen Theil deutlich hervorwölbte, während die zweite Systole gewissermassen nur als Fortpflanzung einer entfernteren und darum auch schwächeren Erschütterung zur Geltung kam. An der Spitze des Herzens werden übrigens auch heute beide Systolen mit gleicher Intensität gefühlt. Die Art und Weise des nach der Punction entstandenen Ausgleiches der bestandenen Störungen der Circulation, soweit von der Radialis und dem Bulbus venae jugularis her kenntlich, ergeben die von ihnen gewonnenen Curven.

13. 6. Patientin geht umher, trägt in der Lebergegend eine mit kaltem Wasser gefüllte Blechflasche, fühlt sich im Ganzen wohler. Der Puls ziemlich regelmässig, 64 in der Minute, etwas voller, scheinbar nicht dikrotisch und gleich häufig wie die Herzaction auftretend.

21. 6. Unter der permanenten Eisblase auf der Leber hat diese ihre Schmerzhaftigkeit verloren und ist etwas kleiner geworden. Die Herzaction ist seit zwei Tagen fast ganz die normale mit einer geringeren Häufigkeit; jedem Herzstoss entspricht ein Puls an der Radialis, derselbe ist mässig voll, ziemlich gespannt nicht celer. Venenpuls nicht vorhanden, ja die Halsvenen kaum deutlich ausgesprochen. An der Herzspitze ein systolischer Ton neben einem systolischen Geräusch hörbar, ihm folgend ein diastolisches Geräusch. Die Diastole ist nicht besonders lang, sondern entspricht mehr den gewöhnlichen Verhältnissen. Zweiter Pulmonalton klappend. Urinsecretion unvergleichlich reichlicher, zwischen 1400-1800 schwankend, Ascites hat sich nicht wieder angesammelt. Pat. wird aus der klinischen Behandlung entlassen.

Vergleichen wir diesen Krankheitsfall mit dem vorigen, so finden wir beiden gemeinsam das Missverhältniss in der Schlagzahl des Herzens zur Anzahl der Arterienpulse. Auch hier schien żunächst zwei systolischen Erhebungen des Herzens nur eine an der Radialis zu entsprechen; aber die Art und Weise, in welcher je zwei Herzsystolen auf einander folgten war wesentlich anders als im vorhergehenden Fall. Die Systolen erschienen ganz auffallend kurz hinter einander, wie kaum bei der beschleunigtesten Herzaction, und waren von der nächsten dritten und vierten Systole durch eine ganz auffallend lang anhaltende Diastole getrennt.

Die beistehenden Curven No. 13 und 15 von der äus-

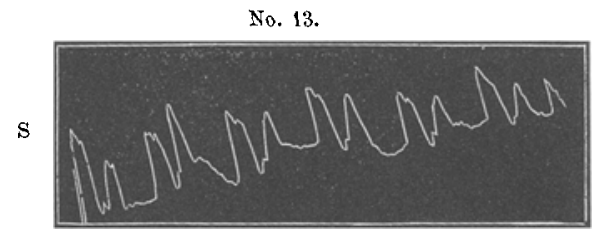


No. 14.

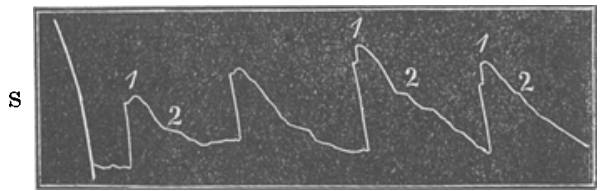

No. 15.

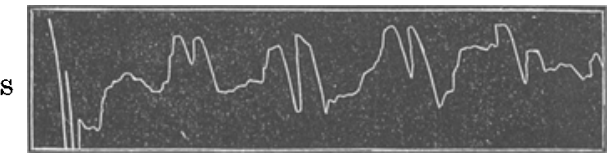

No. 16.

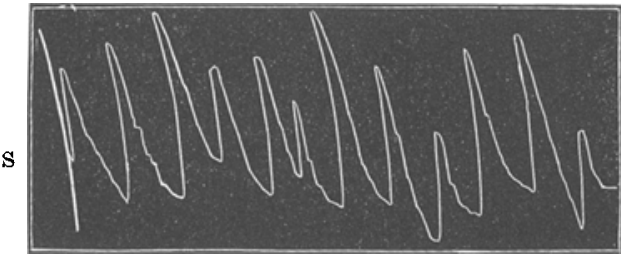

Venenpuls. Gutzeit. 20. 5. T6. Schr: sersten linken Begrenzung des Spitzenstosses und beziehung:sweise vom unteren Theile des Sternums genommen zeigen die schnell hinter einander folgenden zwei systolischen Erhebungen, die ihrerseits von langen Diastolen eingeschlossen sind. Bericksichtigt man ferner, dass auch hier in der Carotis (Pulscurve No. 14) nur ein fühlbarer Puls auf zwei Herzsystolen kam, während am Bulbus venae jugularis (Pulscurve No. 16) und der Vena jugularis, deren eben so viele erschienen, wie die Contractionen des Herzens, so lag abermals der Gedanke an eine doppelte gesonderte Action des rechten Ventrikels nahe, um so mehr als in diesem Falle die gewonnenen Pulsbilder eine so auffallende Aehnlichkeit mit den von Leyden ${ }^{1}$ ) in der Neuzeit veröffentlichten und in der genannten Weise gedeuteten zeigten. Aber bei genauerem Studium der von der Carotis gewonnenen Curven zeigte sich constant die bei 2 ausgeprägte kleine Erhebung, welche der Zeit nach genau dem zweiten Herzstoss entsprach. War man nun berechtigt diese kleine Erhebung als selbstständigen Carotispuls anzusehen, oder beeinflusste vielleicht die stark pulsirende Jugularvene hier die Bewegungen beziehungsweise die Zeichnungen an der Carotis, wie wir es sonst umgekehrt bäufiger finden.

No. 17.

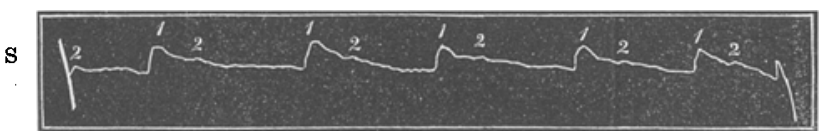

Die nebenstehende Radialiscurve (No. 17) zeigt, dass diese mit der in Caro-

tiszeichnung der Lage nach und auch sonst übereinstimmende kleine Erhebung in der That in der Arterie selbst zu Stande kam, dass wir in ihr somit einen rudimentären Puls besassen, der aus der zweiten der beiden kurz auf einander folgenden Systolen resultirte.

1) Virchow's Archiv. Bd. 65. H. 2. 
Für letzteres sprach einerseits das in der Zeichnung sichtbare mit der ihr vorangehenden Herzzeichnung correspondirende nähere Herantreten der Erhebung 2 an 1, der auf zwei folgende lang gezogene absteigende Schenkel, sowie die im Status praesens notirten Töne uber der Aorta und in der Carotis zur Zeit der zweiten systolisehen Erhebung des Herzens beziehungsweise im Moment in dem diese kleine Erhebung sicht- und fuhlbar zu Stande kam - Töne, die nur entstanden gedacht werden konnten, indem Blut mit der zweiten Systole in die Aorta hineingetrieben, in der Diastole gegen die Semilunaren derselben zurückschlug, $d$. h. dass ein selbstständiger Puls gebildet wurde. Diese interessanten Erscheinungen am Herzen und am Pulse blieben Tage lang constant bestehen, während sie an anderen Tagen für viele Stunden einer mehr unregelmässigen Pulsation Platz machten, deren graphische Darstellungen hier wohl übergangen werden können. Während dieser Zeit wurde die Kranke mit Digitalis, dann mit anderen Diureticis und Diaphoreticis behandelt, ohne einen wesentlich günstigen Einfluss auf das Befinden derselben. Sogleich nach der Punktion (5. Juni) der Abdominalhöhle gleichzeitig mit dem Eintritt allgemeiner Besserung begann der Puls sich schnell zu ändern: zunächst trat ein deutlich pulsirender Lebertumor hervor, dessen Pulsationen in der Zahl mit denen der Jugularis ubereinstimmten, letzterer selbst wurde deutlich alternirend, während die zweite kleine Erhebung in den Arterien kenntlicher auch für das Gefühl hervorzutreten begann. Die Herzaction ergab der zuerst gezeichneten analoge Curven.

Von den folgenden drei Curven ist No. 18 von der Jugularvene, No. 19 von der Carotis, No. 20 von der Cubitalis genommen.

No. 18.

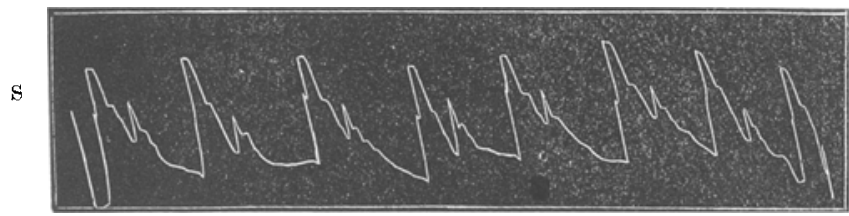

No. 19.

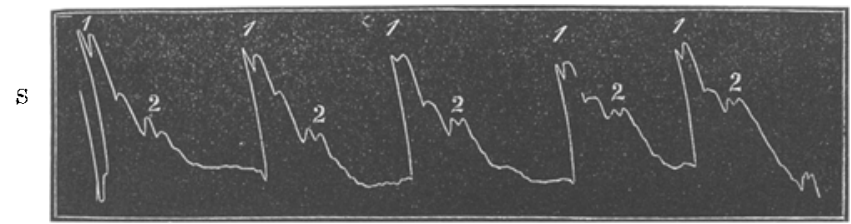


No. 20.

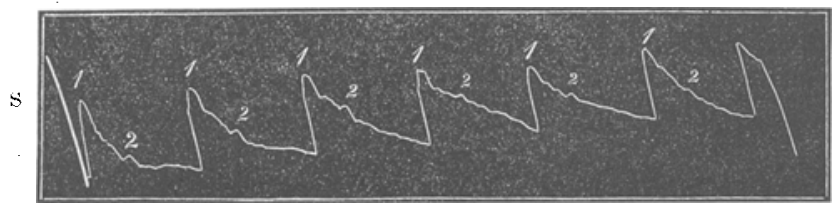

Es ist vielleicht nicht ohne Interesse eine Curvenzeichnung des zuvor erwähnten Lebervenenpulses hier einzuschalten; sie ist von der Gegend des rechten Lappens gewonnen, um etwaige der Leber von dem Herzen mitgetheilte Bewegungen möglichst ausschliessen zu können.

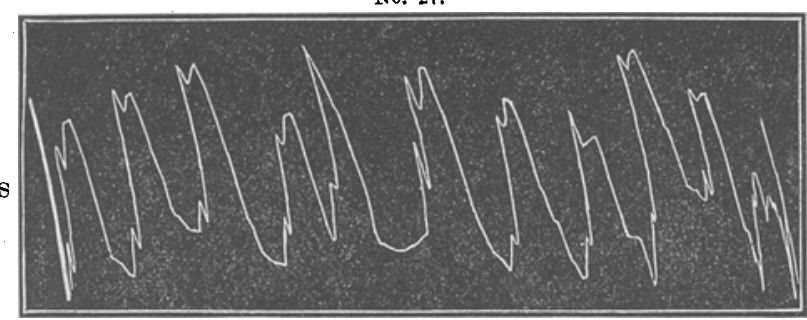

Der Puls charakterisirt sich als wirklicher in der Leberselbstdurch rhythmische Fullung and Entleerung derselben entstandener (und

offenbar hier durch eine relative Tricuspidalisinsufficienz bedingter) Puls durch seine deutlich ausgesprochene Anadikrotie, die nicht vom angrenzenden Herztheil herrihite, weil erstens derselbe zu entfernt lag, vor Allem aber, weil die vom Herzen selbst zu gleicher Zeit gewonnenen Curven keine Anadikrotie zeigen. Diese Bewegung der Leber als eine etwa noch von der Bauchaorta mitgetheilte anzusehen ist darum nicht gestattet, weil die Pulsationen der Bauchaorta sich in der Femoralis kundgaben, diese aber sich analog der obigen von der Carotis verhielten. Die Leberpulsation bestand übrigens mit solcher Deutlichkeit nur ca. 2 Stunden und war nach einer plötzlichen freudigen Gemulthsbewegung aufgetreten.

Um jedoch zu den uns specieller interessirenden Pulsphänomenen zuriickzukehren, so wurden, je wohler und freier von Beschwerden sich die Kranke fühlte, die zweiten Erhebungen des bereits alternirenden Venenpulses desto kleiner sich den anfangs abortiven in den Arterien nähernd, letztere selbst aber immer deutlicher zu deutlich futhlbaren Pulsen anschwellend.

No. 22 .

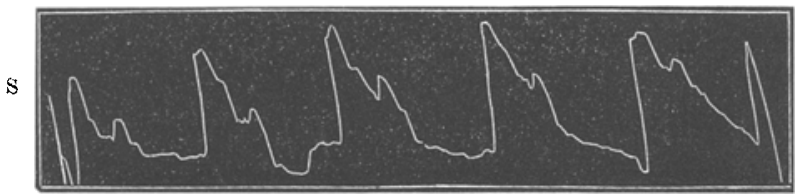


No. 23.

S

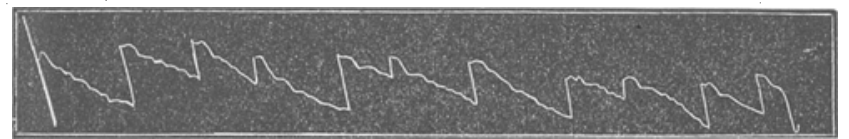

No. 22 von dem Bulbus venae jugularis, No. 23 von der Art. cubitalis gewonnenen Curven machen es wohl uberflussig noch die Ergebnisse der Palpation tiber den genannten Gefässen hier auseinander zu setzen, sie entsprechen eben dem, was die Zeichnungen deutlich zeigen.

Etwa 14 Tage nach der Punktion war der Venenpuls an der Jugularis allmählich undeutlich geworden und hatte schliesslich aufgehört wie es der Lebervenenpuls bereits viele Tage vorher gethan hatte. Die Herzaction wurde annähernd normal und nur hin und wieder zeigte sich die Neigung einzelner Herzphasen mit einer kürzeren Diastole näher aneinander zu treten und nur dann erschienen auch am Pulse sofort Zeichen des alternirenden.

Diese drei Curven, No. 24 von der äussersten Begrenzung des Spitzenstosses, $\mathrm{s}$ No. 25 von der Art. cubitalis, No. 26 rom unteren Theile des Sternums sind solche

Durchschnitts- s curven aus den letzten Tagen des Aufenthaltes der Kranken in der Klinik; sie be- ${ }^{\text {s }}$ leuchten das Vorhergesagte zur

No. 24.

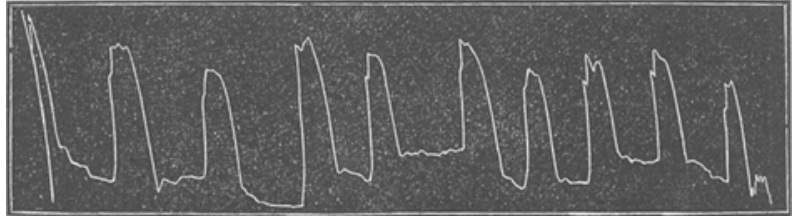

No. 25.

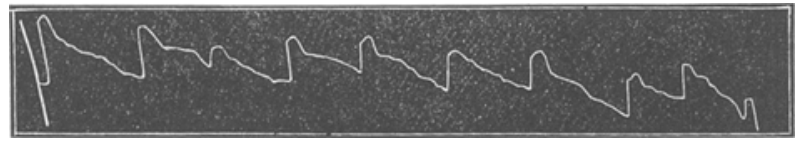

No. 26 .

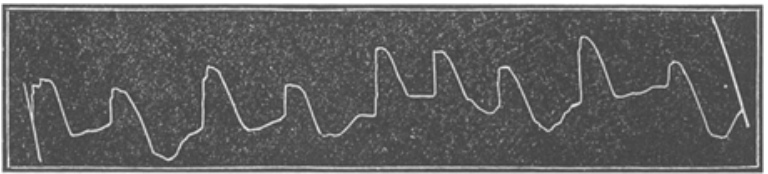

Genüge. Die Kranke verliess hiernach die Klinik, in die sie schwer leidend aufgenommen worden war, subjectiv ausserordentlich, aber auch objectiv nicht unwesentlich gebessert. So weit ich - beiläufig - vor wenigen Tagen durch eine Verwandte der Kranken richtig benachrichtigt bin, fuihlt sich letztere noch immer wohl und scheint der Ascites bei derselben mindestens nicht in der früheren Ausdehnung wieder hervorgetreten zu sein.

Den dritten hierher gehörigen Fall habe ich leider nur voruber- 
gehend beobachten können; es betraf derselbe einen Lehrer aus der Provinz, der sich wegen zeitweise auftretender Ohnmachten in der hiesigen medicinischen Poliklinik vorstellte und bei dem es mir auffiel, dass die Herzaction nach irgend erheblichen Bewegungen sich in der eigenthümlichen Weise veränderte, wie sie für den doppelten Spitzenstoss charakteristisch schien. In den nächsten Minuten verschwand das Phänomen jedoch, um der gewöhnlichen weiter unten näher zu bezeichnenden regelmässigen Herzaction Platz zu machen. Ich glaubte in dem Fall eine Vermittelungsform für die beiden hier allein in Frage kommenden Zustände: doppelter Spitzenstoss oder Pulsus alternans beziehungsweise eine Erklärung für die Entstehungsweise der letzteren erblicken zu dürfen. Eine mehrtägige Beobachtung des Patienten in der Klinik hat, wie das Weitere zeigen wird und wie ich glauben möchte, meine Vermuthung bestätigt.

Der Kranke, Friedrich E., 34 Jahre alt, erzählt, dass er bis vor 7 Jahren im Wesentlichen gesund gewesen, damals eine Lungenentzündung überstanden und seitdem bis zum Herbste vorigen Jahres sich wieder wohl befunden habe. Um diese Zeit stellte sich beim Steigen von Treppen, beim Bücken oder stärkeren Körperbewegungen ein Gefuhl von Druck in der Magen- und Lebergegend ein, das ihn bis heute nicht mehr verlassen hat. An Kurzathmigkeit, Stichen auf der Brust, Herzklopfen, hat Patient angeblich nie gelitten; dagegen hat sich öfters ein so starkes Schwindelgefuhl gezeigt, dass der Kranke wiederholt in Folge hiervon umgefallen und für kurze Zeit das Bewusstsein verloren haben will. Im letzten Winter hat Patient in seinem Auswurf zweimal etwas hellrothes, schaumiges, spärliches Blut bemerkt. - Der Kranke ist ein mittelgrosser, sehr kräftig angelegter Mann von gutem Ernährungszustand, die Hautfarbe sehr blass, die Respiration ruhig oberflächlich, weder Cyanose noch Oedem; Puls auffallend langsam, 26 in der Minute, hoch, voll, langsam ansteigend, mit ziemlich erheblicher Resistenz. Auf der Höhe des Pulses erfolgen einige kurze Vibrationen, so dass man von demselben eigentlich nicht als von einem langsamen sprechen kann, denn es hat der palpirende Finger das Gefühl, als ob die Arterienwelle zu einer bestimmten Höhe schnell ansteigt, hier angelangt aber einige schnelle Vor- und Rückwärtsbewegungen mache, hierauf ziemlich schnell mit schliesslich abnehmender Geschwindigkeit abfalle. Es ist dieses Phänomen an allen der Palpation zugänglichen Arterien mit grosser Deutlichkeit fühl- an den Carotiden auch noch sichtbar. - Die active Rúckenlage, die der Kranke zur Zeit der Untersuchung wegen einnimmt, kann er mit jeder anderen Lage beschwerdelos 
wechseln, doch hebt er ungefragt hervor, dass er die linke Seite im Ganzen bevorzuge. Seine subjectiven Beschwerden beziehen sich auf ein Druckgefühl in der Magen- und Lebergegend. Bei weiterem Nachfragen ergänzt Patient seine anamnestischen Angaben dahin, dass er seine eigenthumliche Herzaction bereits seit vielen Jahren kenne, dass dieselbe sich allmählich entwickelt und sobald er sich keiner anstrengenden Thätigkeit aussetze, ihm auch gar keine Beschwerden weiter bereite. Im entgegengesetzten Falle dagegen träten Herzklopfen auf, das Herz schlage dann ganz anders und einzelne Herzschläge fehlten manchmal ganz. Gesichtsfarbe sowie die sichtbaren Schleimhäute des Gesichtes sehr blass, Hals von gewöhnlicher Länge, die oberflächlichen Venen daselbst treten als schwach-blaue Linien, die bei Hustenstössen deutlicher werden, sichtbar hervor. Vor allen Dingen fällt hier aber auf, dass die vordere Halspartie, von den äusseren Partien der Sternocleidomastoidei ab, rhythmisch und zwar mit jeder Herzsystole förmlich in die Höhe getrieben werde. Es gibt sich hier beziiglich der Bewegung der pulsatorisch emporgeschnellten Halshaut das deutlich sichtbar zu erkennen, was für die Radialis bezüglich der Palpation beschrieben worden. Eine selbstständige Bewegung der Venen ist nicht zu constatiren. - Der Thorax mehr ektatisch gebaut zeigt eine Hervorbuckelung der linken Seite sowie der linken Hälfte des Sternums von der zweiten bis inel. sechsten Rippe von der Median- und Mammillarlinie seitlich begrenzt, diese Voussure iberragt eine durch die normalen Brustpartien gelegte Ebene in ihrer höchsten Höhe um etwa 1 bis $1 \frac{1 / 2}{C}$ tm. Sonst zeigt der Thorax und ebenso die Perkussion und Auscultation der Lungen ausser auf der linken vorderen Seite keine Abweichung von der Norm. Die Herzdämpfung beginnt linkerseits unterhalb der zweiten Rippe, und zwar bis zur vierten Rippe mässig, von hier bis zur sechsten Rippe intensiv gedämpft; die Dämpfung beginnt oben etwa $2 \mathrm{Ctm}$. vom linken Sternalrand entfernt, geht als linke Begrenzung in einer von hier durch die Mammilla gelegten schrägen Linie, die an der Stelle des Spitzenstosses im fünften Intercostalraum endigt. Nach rechts ist die Dämpfung iiber die Medianlinie hinaus nicht mit Sicherheit $\mathrm{zu}$ verfolgen, dageg'en reicht sie ziemlich hoch hinauf längs des Sternums. Der Spitzenstoss ist im fünften Intercostalraum in der Linea mammillaris ziemlich diffus und massig und doch circumscript und kräftig zu fühlen. Die durch die vorgenannten Linien begrenzte Herzgegend tritt als mächtige Voussure, die länglich und schräg von links unten nach rechts oben erscheint, hervor. Ueber dem oberen Theil des Sternums fühlt man ein systolisches Frẻmis- 
sement, das mit einer grösseren Deutlichkeit in der Fossa jugularis und an den Carotiden hervortritt; in ersterer sind ausserdem noch deutliche Pulsationen sicht- und flihlbar. Die Herzaction ist sehr langsam und regelmässig, aber zeitweise verändert sie sich derart, dass auf einen längeren Herzchok ein zweiter kürzerer folgt und hinter diesem eine lange anhaltende Diastole. Diesen beiden Spitzenstössen entspricht bei der oberfiächlichen Prufung des Pulses nur eine, wie es scheint, sehr ausgeprägte dikrotische Pulswelle; bei genauerer Prüfung indess findet man, dass die scheinbare dikrotische Erhebung dem zweiten Spitzenstosse in der Zeit in der gleichen Weise nachfolgt, wie es der Radialpuls in dieser Beziehung gewöhnlich that. Bei der Auscultation an der Spitze ein langgezogenes systolisches Geräusch neben einem dumpfen systolischen Ton, ein kurzer diastolischer Ton. Nach dem unteren Theil des Sternums zu wird zunächst dieses systolische Geräusch kürzer, tonartiger, auf demselben hingegen tritt wiederum ein sehr lautes systolisches Geräusch hervor, das nach oben hin an Mächtigkeit zunimmt, und mit besonderer Deutlichkeit auf dem Manubrium sterni erscheint. Von hier aus ist dasselbe nach rechts und links hin in ziemlich weiter Ausdehnung zu verfolgen, weiter indess nach rechts hin. In der Gegend der Pulmonalis ein kurzes systolisches Geräusch, ein kurzer zweiter Ton; dasselbe im zweiten Intercostalraum rechts 1 Zoll vom rechten Sternalrand entfernt. Ueber der Carotis in der Fossa jugularis ein sehr lautes systolisches Geräusch. Sobald nun jener vorher genannte eigenthümliche Wechsel der Herzaction eintritt, hört man an der Spitze nach dem ersten systolischen Geräusche drei kurz hintereinander folgende etwas dumpfe Töne, entsprechend einer Diastole, Systole, Diastole; dasselbe ist schwächer tiber dem unteren Theil des Sternums und ebenso, nur etwas kürzer, über den Carotiden zu hören. Im zweiten Intercostalraum links scheint hierbei der zweiten Systole ein kurzer Ton zu entsprechen. Ueber der Cubitalis ein deutlicher gedehnter systolischer Ton, uber der Femoralis ein paukender systolischer Ton. Deutlicher Capillarpuls am Nagelbett sämmtlicher Finger. Von weiter hierher gehörigen Notizen aus dem Status sei noch erwähnt, dass das systolische Geränsch anch längs der Wirbelsäule und namentlich links deutlich zu hören ist, dass keine Schmerzen beim Schlucken bestehen, kein erhebliches Druckgefühl, die Stimme dagegen rauh und heiser klingt, ohne dass eine besondere entzündliche Affection des Kehlkopfes nachzuweisen wäre.

Was zunächst die Diagnose dieses Falles betrifft, so glaube ich ohne erheblichen Zwang als den wesentlichen hier bestehenden 
Herzfehler ein Aneurysma der Aorta ascendens und des Arcus aortae wohl annehmen zu dürfen, wenigstens scheint mir dafür die Art der Voussures und der hoch auf das Sternum sich hinaufziehende, wenn auch nur schwachen Dämpfung, das sehr laute systolische Geräusch tiber der Aorta bei einem sehr vollen hohen resistenten Pulse und bei einem exquisiten Capillarpulse, sowie die mässig deutlich ausgesprochene Verspätung sämmtlicher Pulse, das nachträglich hier noch Erwähnung finden mag, und vielleicht die etwas rauhe Stimme des Kranken zu sprechen.

Dieser Kranke zeigte nun für gewöhnlich, wie schon angedeutet, eine sehr langsame Herzaction. So oft er aber sich nur mässigen körperlich anstrengenden Bewegungen aussetzte, was er zur Untersuchung wiederholt that, dann trat für 5-10 Minuten eine Action am Herzen und ein Puls an den Arterien auf, die zu nachstehender graphischer Darstellung Veranlassung wurden. Ich glaube kaum zur Erklärung der folgenden Pulsbilder, von denen No. 27 den Spitzenstoss, No. 28 den Cubitalpuls, No. 29 den Herzstoss am unteren Theil des Sternums darstellt, etwas hinzufügen zu müssen; zu betonen wäre vielleicht noch die Abweichung dieses Falles von den beiden vorigen, dass bei ihm weder ein mit der Herzaction gleich häufiger noch ein Venenpuls iberhaupt jemals constatirt werden konnte.

Von dem zuletzt erwähnten Gesichtspunkte aus sei es gestattet, hier nur noch einen Fall mit möglichster Kürze anzufügen. Es betraf derselbe einen Grenzsteuerbeamten, Gustav B., der im Wesentlichen stets gesund gewesen sein will; im December vorigen s Jahres sei sein jetziges Leiden, das er auf häufige Erkältung als Ursache bezieht, unter den Erscheinungen von Athemnoth a. Brustbeklemmung u. spä-

No. 27.

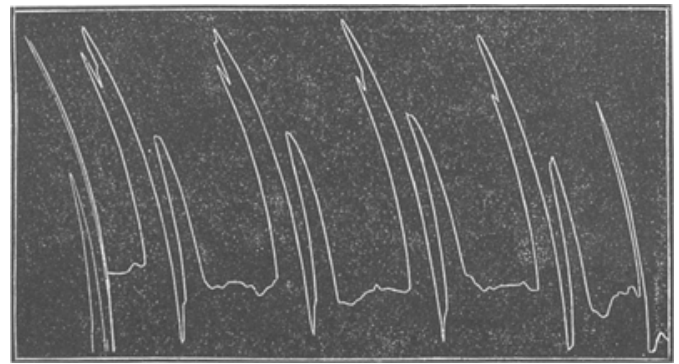

No. 28 .

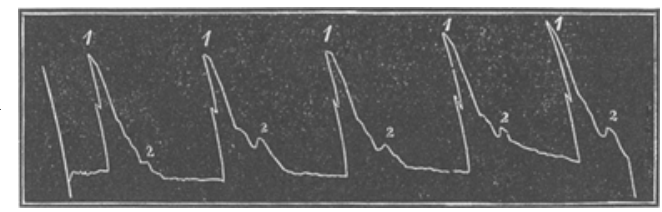

No. 29 .

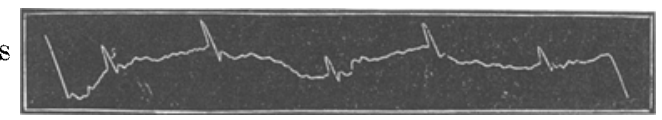


terer Schwellung der unteren Extremitäten aufgetreten. Der Kranke ist ein gut gebauter, kräftig angelegter Mann in ziemlich gutem Ernährungszustande; die Hautfarbe im Gesicht cyanotisch, im Uebrigen anämisch. Deutliches Oedem der unteren Extremitäten bis zum Knie, der Puls sehr frequent, regelmässig, klein und weich. Patient liegt in activer Rückenlage mit etwas erhöhtem Oberkörper, meidet die linke wegen hierbei auftretender Beängstigung und wählt mit Vorliebe die rechte Seitenlage. Man findet den Thorax sich ungleich ausdehnend, die rechte Seite scheint bei der Respiration sich gar nicht $\mathrm{zu}$ betheiligen. Wir finden an ihr die gewöhnliohen Zeichen eines sehr hochgradigen pleuritischen Ergusses, während links hinten normale Auscultations- und Perkussionsverhältnisse bestehen; links vorn in der Fossa supraclavicularis und im ersten Intercostalraum normaler Lungenschall, desgleichen im zweiten. Auf der dritten Rippe beginnt eine Dämpfung, die bald absolut wird und so bis zur sechsten Rippe anhält, diese Dämpfung ist nach rechts hin wegen des bestehenden hochgradigen rechtsseitigen pleuritischen Ergusses nicht abzugrenzen. Nach links ziebt die 11/2 Ctm. voim linken Sternalrand beginnende obere Dämpfung in einer zur Schulter schwachen Bogenlinie, die sich 2-21/2 $\mathrm{Ctm}$. von der linken Mammillarlinie nach aussen entfernt hält, zur Stelle des Spitzenstosses hin, der in der gleichen Entfernung von der Mammilla im fünften Intercostalraum gelegen ist, derselbe ist nur undeutlich fuhlbar und man hört uber ihm neben zwei leisen und wie es scheint reinen Tönen ein in der Exspiration besonders hervGrtretendes, mehr schabendes Geräusch, das an keine der beiden Herzphasen sich genau bindet. Sonst sind über dem Herzen nur auffallend leise Töne zu hören. Abdomen mit mässigem ascitischem Erguss; die wenig schmerzhafte Leber die Nabellinie erreichend; der Urin spärlich, von hohem specifischen Gewicht und Eiweiss ènthaltend.

Die aus dem Status hier gegebenen Daten genilgen, um die fuir die Circulation wichtigsten Veränderungen, die hochgradige Pleuritis und einen Erguss irn Pericard als Diagnose nennen zu dürfen. Mit diesem Befunde wurde der Kranke am 11. Februar d. J. in die Klinik aufgenommen. Am 21. waren die Erscheinungen dieselben, der Puls sehr frequent bis 140 und darüber, worauf hin dem Kranken ein Digitalisinfus von 1,0:170,0 mit Tartarus depuratus 10,0, 2 stdlch. 1 Essl. verordnet wurde. Puls und Herzaction waren bis dahin regelmässig gewesen, wie die Curve No. 30 (s. S. 339) zeigt.

Ich gebe dieselbe nur hier wegen der systolischen Einziehung, um zu zeigen, dass dieselbe bereits vor der nächsten. Veränderung 
bestanden habe. Am 23. hatte die Dyspnoe etwas zugenommen und Abends schien der Puls von 140 bis auf zwischen 70 und 80 heruntergegangen zu sein; aber bei genauerem Zufühlen des Arterienpulses zeigte sich jene kleine Welle zwischen zwei Pulsen, die mich sofort veranlasste die Herzaction genauer zu untersuchen, die aber nach wie vor über 140 Schläge darbot. Es war somit abermals ein Pulsus alternans aufgetreten. Am folgenden

No 30 .

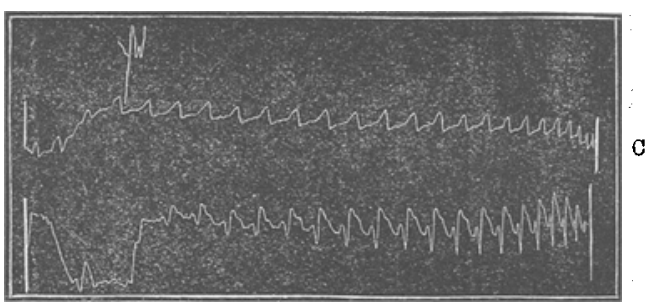
Tage (24. Febr.) wurden aus der rechten Pleurahöhle 1500 C.-Ctm. einer hellen gelblich grünlichen Flüssigkeit entleert. Die Digitalis wurde in der vorgenannten Dosis weiter gebraucht. Die an diesem Tage aufgenommene sphygmographische Curve ergab folgende Zeichnung, in der die obere von der Radialis, die untere von der Stelle des Spitzenstosses stammt. Bis zum 26. hielt diese eigenthümliche Herzaction an, sie schwand an dem genannten Tage unter zunehmender Diurese und unter Abnahme der Anzahl der Pulse auf 90 in der Minute; der Puls wurde voller und etwas resistenter, bei Fortgebrauch des vorgenannten Digitalisinfus. Bis heute (2. März) ist der alternirende Puls nicht wieder aufgetreten, obwohl die Behandlung noch immer dieselbe ist.

No. 31 .

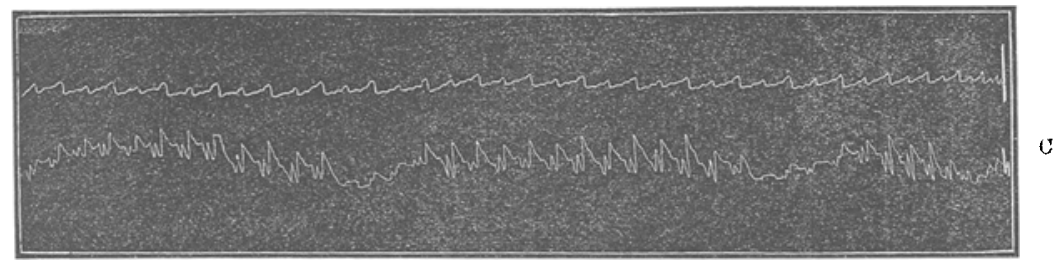

Bisher habe ich es versucht mit Hïlfe der Her's- und Pulscurven die Entwicklung der kleinen zuweilen eben nur angedeuteten zweiten Erhebung im absteigenden Schenkel der Arteriencurven zum deutlichen Pulsus bigeminus oder alternans nachzuweisen; aber es wäre vielleicht immer noch der Einwand gestattet, dass diese Erhebungen als sogenannte Rückstosselevationen Landois', grosse Ascensionen Wolff's oder als Theile des gewöhnlichen di- oder trikrotischen Pulses angesehen werden könnten. Gerhard ${ }^{1}$ ) sagt

1) Lehrbuch der Auscultation u. Perkussion. 1876. S. 88. 
z. B. in der neuesten Auflage seines Lehrbuches noch ganz direct: "eine andere seltene, aber interessante Begrtindungsweise desselben (des P. dicrotus) findet sich mit manchen Fällen von doppeltem Herzstosse vor und beruht darauf, dass die Systole des linken Ventrikels in zwei Absätzen erfolgt", während Tschiriew") eine äbnliche Herzthätigkeit für das Zustandekommen des Pulsus bigeminus in Anspruch nimmt; derselbe ,ist ein einfach verlangsamter Puls, bei dem die Herzkammer sich peristaltisch contrahirt". Dieser Zweifel schwindet indess vollends durch die experimentell und durch Beobachtungen an Kranken gestitzte Definition des dikrotischen Pulses gegenuber dem alternirenden oder Pulsus bigeminus: als ersteren bezeichnen wir einen aus einer primären grösseren und einer secundären geringeren Welle bestehenden Puls, dem nur eine Contraction des Herzens entspricht; als Pulsus bigeminus bezeichnen wir das Phänomen, sobald die zweite Welle - wie gross oder klein sie auch sein mag - einer zweiten der ersten gleich starken oder schwächeren Herzcontraction entspricht. Diese Forderung haben wir in unseren Fällen von Anbeginn der kleinsten Erhebung bis zu ihrem Wachsen stets erfullt gefunden. Aber es könnte vielleicht die Pulswelle an den Arterien ihrerseits ihren gewöhnlichen dikrotischen Verlauf genommen, während trotzdem eine zweite Contraction etwa nur des rechten Herztheiles sich zwischen eingeschoben und so die Doppelthätigkeit des Herzens könnte bewirkt haben; auf die Berechtigung dieser Frage will ich gleich ausführlicher eingehen, nachdem ich zuvor noch aus anderen Momenten die obigen Pulse als alternirende gekennzeichnet. Wir wissen, dass die jeweilige Lage der dikrotischen Erhebung eines Pulses $x \alpha{ }^{3}{ }^{3} \xi \xi_{\alpha} \chi \eta^{\prime} \nu$ abhängig ist von der Zeit resp. in der Zeichnung, die dikrotische Erhebung der Curve abhängig ist von der Lage, in der der Schluss der Semilunarklappen erfolgt; dass die Lage der dikrotischen Erhebung somit, sobald wir die betreffende Arteriencurve unter die in Beziehung $\mathrm{zu}$ ihr stehende Herzcurve setzen, zwischen zwei Elevationen der letzteren fallen muss; denn zwischen denselben hat nothwendig eine Diastole id est eine Entfaltung der Semilunaren stattgehabt. Betrachten wir aber unsere obigen Curven von diesem Gesichtspunkte aus, so fällt die fragliche Erhebung stets hinter die zweite der gezeichneten Herzcontractionen und ist somit nothwendig als Folge derselben id est als selbstständiger Puls anzusehen, d. h. es handelt sich um einen

1) Einfluss des Blutdrucks auf das Herz (Orig.-Mitth.). Centralbl. f. d. med. Wissenschaften. No. 35. 1876. 
Pulsus bigeminus oder alternans. Aber wo immer ein Puls, sei er auch noch so gering, gebildet wird, dürfen wir wohl auch die durch ihn bedingte Spannung der Arterienwand und den durch die riickläufige Welle bedingten Klappenschluss durch die Auscultation nachweisen können? Die vorstehenden Krankengeschichten ergeben das Genauere hiertiber und beantworten die Frage zu Gunsten der Auffassung obiger kleinen Erhebungen im absteigenden Schenkel als selbstständiger Pulse, als alternirende oder bigemine.

Ich komme nunmehr zur Beantwortung der Frage nach einer in unseren Fällen etwaig aufgetretenen doppelten Contraction des rechten Ventrikels. Ich gestehe zunächst, dass ich nach dem anatomischen Bau dieses Organes mir nicht recht denken kann, wie der eine Ventrikel sich contrahire, ohne dass der andere unweigerlich in jenen Zustand mit tiberginge; ein Organ mit theilweise gemeinsamer Musculatur, mit einem gemeinsamen nervösen Centralapparate, das sogar noch unter bestimmten Verhältnissen ausserhalb des Körpers, wenn der nothwendigste Impuls, der Eintritt von Blut aus den Gefässen beziehungsweise den Vorhöfen, gebricht, sich in toto zu contrahiren vermag, wird kaum, ich möchte sagen, so unnatürlich sich im lebenden Organismus verhalten können, wenn Aehnliches auch bei absterbenden Herzen beobachtet ist. Und wie sollten wir uns wohl diese gesonderte Action der Ventrikel vorstellen? Wir vermöchten es doch nur in der Annahme, dass entweder der eine, der linke, seinen diastolischen Zustand nach der ersten gemeinsamen Contraction gar nicht veränderte, während der andere, der rechte, sich contrahirte; oder aber dass in der Zeit der ersten Diastole und zweiten Contraction des rechten Ventrikels der linke Ventrikel in krampfhafter Contraction auf seiner ersten Systole verharren bliebe - das wäre, wie ich glaube, bei den mannigfach gemeinsamen durchflochtenen Muskelzügen beider Herzhälften nicht leicht denkbar: vielleicht aber auch würde in den fraglichen Fällen der linke Ventrikel durch die alleinige selbstständige Contraction des rechten mitgezogen, mitcontrahirt, dann aber hört die gesonderte Contraction der Ventrikel auf eine solche wirklich zu sein und es träte die Beantwortung der Frage in den Vordergrund, ob etwa der Impuls zur Contraction in unseren Fällen vom rechten Ventrikel ausgegangen resp. weiter, ob dieser Impuls uberhaupt von einem bestimmten Ventrikel vorzugsweise ausgehe. Aber wie dem auch sei, so misste man praktisch zum mindesten das erwarten, dass der allein oder im Ueberwiegen sich contrahirende Ventrikel sich in derselben Weise schon palpatorisch auszeichnen werde, wie es der linke so häufig 
thut. Indess bei genauerer Durchsicht der vorgestellten Krankengeschichten und der daza gehörigen Herzzeichnungen finden wir, dass der zweite der beiden Spitzenstösse stets schwächer und sich nach rechts hin weniger fühlbar machte, ja dass im zweiten Fall nach Entleerung des Ascites, wonach man bequem unter dem Process. xiphoides eingehen und den darunter gelegenen, doch wohl rechten Herztheil durch das Zwerchfell hindurch deutlich palpiren konnte, bestimmt die zweite Pulsation als eine in der Gegend dieses Herzabschnittes nur undeutlich wahrzunehmende, gleichsam nur wie eine fortgeleitete erkannte. Wie trotzdem die Erscheinungen und das Ergebniss der Pulszeichnungen an den Venen und Arterien sowie der vom Herzen sich im Sinne einer gesonderten Contraction des rechten Ventrikels verhalten konnten, das werde ich weiter unten zu beantworten versuchen. Diese gesonderte, ungleichzeitige Contraction beider Ventrikel ist bereits von $\mathrm{Charceley}^{1}$ ) in einigen Fällen beobachtet und als Dyschronismus der Ventrikel ausfihrlich beschrieben worden; Williams und $\mathrm{Sk}$ oda erwähnen derselben als Ursache der gespaltenen Töne und neuerdings hat auch Ley den ${ }^{2}$ ) in drei Fällen jene eigènthümliche Herzthätigkeit mit sphygmographischen Curven darzuthun versucht. Wie weit die meinigen und namentlich die drei ersten, die mich speciell an die von Leyden sehr erinnerten, ihnen wirklich gleich oder ähnlich sind, das möchte ich nicht $\mathrm{zu}$ entscheiden wagen. Sie gaben mir indess Veranlassung der Beantwortung dieser Frage auch experimentell näher zu treten, zumal die Zulässigkeit der Ley den'schen Auffassung wenigstens für Thiere, die unter bestimmte pathologische Verhältnisse gebracht wurden, von $\mathrm{Hofmokl^{3 }}$ ) und $\mathrm{Klebs}{ }^{4}$ ) nachgewiesen schien.

Hofmokl fand bei Gelegenheit seiner unten genauer angegebenen Untersuchungen Folgendes: „Lässt man das Thier (curarisirt) bei „durchschnittenen Vago-sympathicis längere Zeit hindureh ohne Athmung, und zwar so lange, bis der Druck im grossen Kreislauf absinkt, so stellt sich die eigenthümliche Erscheinung heraus, dass der rechte Ventrikel eine grössere Frequenz bietet als der

1) Mémoire sur plusieurs cas rémarquables de défaut de synchronisme des battements et des bruits des ventricules du coeur. Charcelai. Arch. génér. Dec. 1838, bez. Schm. Jahrb. Bd. XXII. S. $291 \mathrm{ff}$.

2) Ungleichzeitige Contraction beider Ventrikel. E. Leyden. Virchow's Arch. Bd. 44. S. 365 u. Bd. 65 . S. 153.

3) Untersuchungen über die Blutdruckverhältnisse im grossen und kleinen Kreislauf von Dr. Hof mokl. Medicinische Jahrbücher (Stricker IX. Th. 1875).

4) Ueber operative Verletzungen der Herzklappen und deren Folgen. Prof. E. Klebs. Prager Med. Wochenschrift. No. 2. 1876. 
linke und zwar ergibt es sich aus der Untersuchung der im Holzschnitte copirten Curvenstïcke . . . . Curve u. s. w. folgt später . . . . dass auf je swei Schläge des rechten je ein Schlag des linken Ventrikels kommt." $H$. wählte zu diesen vergleichenden Messungen ,im grossen Kreislauf die Carotis communis, im kleinen bei einseitig offenem Thorax und geschlossenem Mediastinum der vorderen Seite einen der Hauptäste der Art. pulmonalis." Wie wenig auch die Lebensbedingungen einés curarisirten, der Möglichkeit zu athmen beraubten Thieres bei den vorgenannten operativen Eingriffen den hier in Frage kommenden Verhältnissen am Krankenbette vergleichbar schienen, so glaubte ich dennoch diesen Versuchen ein genaueres Studium widmen $\mathrm{zu}$ müssen. An fünf mittelgrossen Hunden versuchte ich dieser Frage näher zu treten und war bemuiht zunächst das Verfahren $\mathrm{H}$ ofmokl's vollständig nachzuahmen; aber die Thiere erlagen dem Eingriff zum Theil so schnell, dass mir eine nur zu kurze Beobachtungszeit gegeben blieb. Auch schienen mir die Zeichnungen mit dem Schwimmer nicht exact genug; ich fürchtete durch Eigenschwingungen desselben im grossen oder kleinen Kreislauf zu fehlerhaften Curvenzeichnungen und ev. zu feblerhaften Schlissen zu kommen; und dies um so mehr, als die Curven von einem Hauptaste der Art. pulmonalis und von der Carotis wegen ihrer verschiedenen Entfernung von den die Pulszeichnungen bei ibrer Entfaltung stark beeinflussenden Semilunaren mir nicht einmal wenigstens für unseren Zweck, selbst bei der correctesten Zeichnung ganz gleichwerthig schienen. Da es mir überdies weiterhin nicht darum $\mathrm{zu}$ thun war, die weiteren sehr interessanten Hofmokl'schen Versuchsergebnisse zu prüfen, sondern mich nur von der gesonderten Action des rechten Ventrikels unter den obigen Verhältnissen selbst zu überzeugen, so glaubte ich meine Versuche in folgender Weise modificiren zu dürfen: Ich versuchte nach Entfernung des mittleren Brustschildes das Herz freizulegen; auf den deutlich vorliegenden rechten Ventrikel setzte ich eine nach dem Principe der Marey'schen, construirte kleine empfindliche Coquille und brachte in die Carotis in der gewöhnlichen Weise eine Canüle ein; statt der Schwimmer bediente ich mich zweier noch wenig gebrauchter und auf die geringsten Bewegungen sehr gut reagirender Tambours eines Marey'schen Cardiographen; hiernach hatte ich die Bedingungen für die Aeusserung von Bewegungen für den rechten Ventrikel sehr günstig gestaltet, während ich füchten musste, dass etwaige nur geringe Mitbewegungen des linken Ventrikels sich bis zur Carotis hin nicht wiliden geltend machen können. Trotzdem fiel das Ergebniss der 

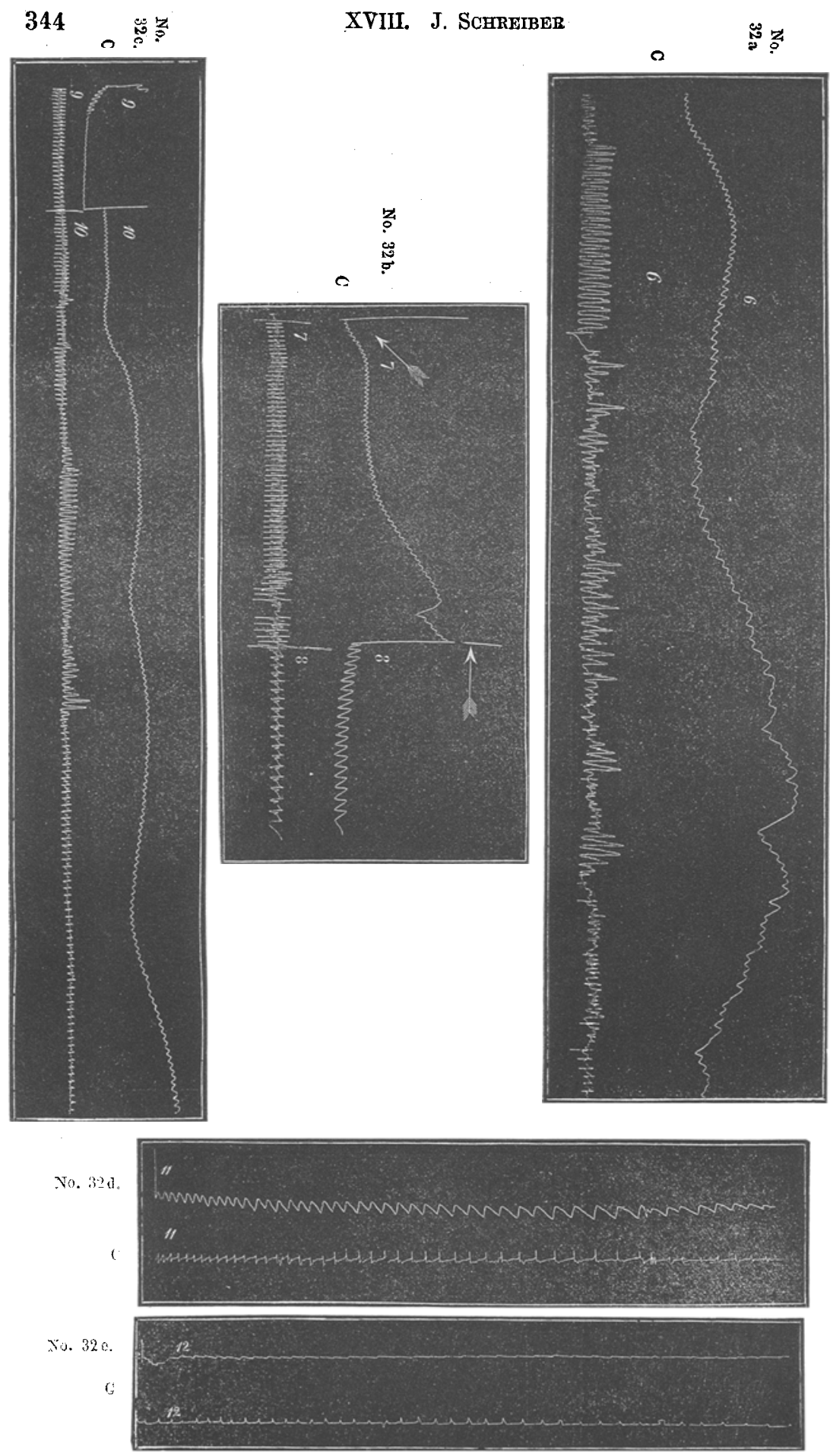
Untersuchungen zu Ungunsten der in Frage stehenden gesonderten Ventrikelcontraction aus, wie es die Zeichnungen S. 344 darthun.

In den vorstehenden Curven, No. 32 a bis $32 \mathrm{e}$ zeigt die untere Reihe die Bewegungen des rechten Ventrikels, die obere die Contractionen des linken Ventrikels von der Carotis aus an. Ich habe die Curven bis zum letzten Herzschlage zu zeichnen versucht: von der Zahl 6-7, No. 32a-32b ist der letzte Theil der Bewegungen im Circulationsapparat vor der Durchsehneidung der Vago-sympathici, von 7 No. $32 \mathrm{~b}$ beginnt die Darstellung der Herzthätigkeit nach ihrer Durchschneidung und nach der Sistirung der Athmung. Um ohne wesentliche Beeinträchtigung des Versuches denselben auf dem einmal aufgespannten Zeichenbogen graphisch zu Ende führen zu können, unterbrach ich durch Arretirung der die Tafel bewegenden Mechanik die Zeichnungen wiederholt, was durch die einzelnen Abschnitte an denselben zu erkennen ist. Wir erkennen an ihnen ausser anderen bekannten Bewegungen mit Deutlichkeit, wie in der unteren Curve die Herzaction immer schwächer und schwächer werdend schliesslich nur noch zu minimalen Erhebungen des Zeichenhebels führte, bis endlich in der geraden Schlusslinie in No. $32 \mathrm{e}$ der Stillstand des Herzens sich andentete. Aber wie klein auch die Ausschläge der Feder von der Herzeurve, wie schwach auch die Thätigkeit des Herzens gewesen war, so traten dennoeh, wie die genauere Prüfung der darïberstehenden Carotiscurve zeigt, selbst bis zum letzten Schlage des rechten Ventrikels noch Andeutungen von Pulsen, die die gleiche Thätigkeit des linken bedeuteten, id est in keiner einzigen Zeitphase war eine doppelte Schlagzahl an der die Bewegungen des rechten Herzens zeichnenden Feder zu bemerken. Zur Controle bemïhte ich mich noch in anderen Versuchen, während ich den Puls in der Carotis in der vorherigen Weise aufschreiben liess, die Bewegungen des rechten Herzens durch den auf ihn leise aufgelegten Finger zu palpiren. Das Ergebniss dieser Versuche war das nämliche. Dass ibrigens die obigen Zeichnungen auch wirklich den Bewegungen des rechten Ventrikels entsprechen, dafür spricht die NNo. 33.

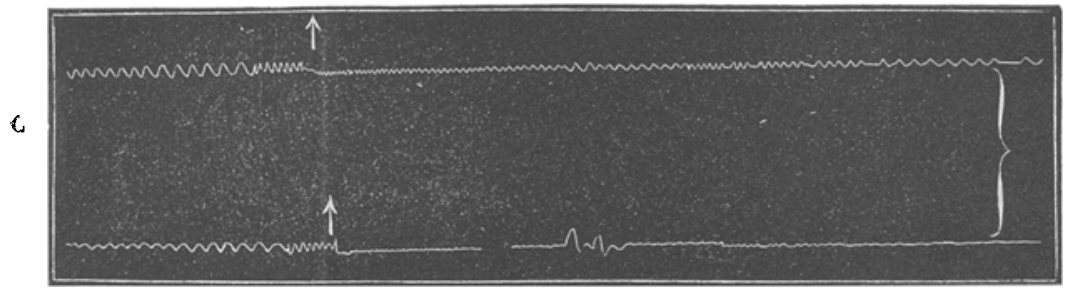


Bestimmtheit, mit der ich infolge der Operationsmethode die $\mathrm{Co}$ quille auf diesen Theil des Herzens setzen konnte.

In der Curve No. 33 ist das Ergebniss eines anderen Versuchs, bei dem an der Stelle der Pfeile die Zeichnung unterbrochen wurde, um die Durchschneidung der Vago-sympathici vorzunehmen; hierauf prufte ich den Versuch in der gleich anzugebenden Weise zum Theil, zum Theil liess ich das constante Resultat aufzeichnen.

Endlich hatte ich noch in einer dritten Reihe von Versuchen Gelegenheit die constante Uebereinstimmung derselben dadurch zu erfahren, dass ich nach den genannten Vorbereitungen die Contractionen des rechten Herzens der Palpation nach bestimmte, während Herr College Langendorf, der mich bei meinen Versuchen in der liebenswürdigsten Weise unterstützte und dem ich hiermit freundlichst danke, die Pulse an der Carotis und der Femoralis zählte. Zur Controle wechselten wir uns an den beiden Organen Herz und arteriellen Gefässen ab und niemals vermochten wir eine Incongruenz in der Schlagzahl beider zu constatiren. Ich habe diese Versuche im physiologischen Institut des Herrn Prof. v. Wit ti ch mit dessen freundlicher Erlaubniss gemacht, wofitr ich hiermit meinen besten Dank ausspreche.

Nach diesen constanten gegensätzlichen Resultaten wirde es sich aber fragen, wie $\mathrm{Hofmokl} \mathrm{zu}$ seinen Versuchsergebnissen gekommen, oder ob etwa seine Curven einer anderen Deutung fähig wären. Zur Beantwortung dieser Frage sei es gestattet die aus der Arbeit Hofmokl's entnommenen Zeichnungen hierher zu setzen.

No. 34 .

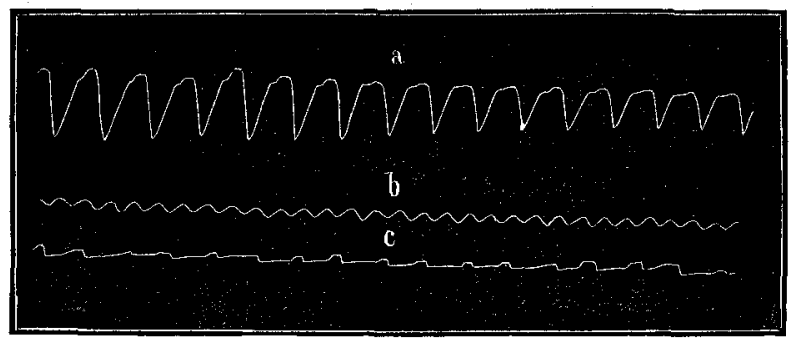

Unter ihnen No. 34 hebt sich sofort an deroberen A. CarotisCurve die con${ }^{\mathrm{K}}$ stante scheinbare Dikrotie jeder einzelnen sehr kenntlich ab, die H. als solche nicht weiter hervorhebt, sondern in der ganzen Figur der Einzelcurven den Ausdruck ,einer systolischen Pause des linken Ventrikels" ersieht. Hiernach scheint $H$. die Vorstellung zu haben, als ob, während der linke Ventrikel in Contraction bleibt, der rechte sich dilatirt, abermals contrahirt und nun erst mit dem linken gemeinsam in die zweite Diastole uibergeht. Da ich nun einmal diese Versuche speciell zu den von Leyden und mir beobachteten klinischen Fällen in Beziehung gebracht, so möchte ich hier gleich zwischen 
einfügen, dass in keinem derselben eine derartige systolische Pause wenigstens vom Herzen her und der Zeichnung nach hat nachgewiesen werden können. Vielleicht aber liegt diese schwer verständliche Deutung H.'s nur in einer nicht ganz richtigen Auffassung der Curven selbst: als ich dieselben zum ersten Male sah, glanbte ich schon nach Maassgabe obiger klinischer Erfahrungen in diesen Katadikrotieen ${ }^{1}$ ) eine zweite durch eine weniger kräftige zweite Contraction zunächst des linken Herzens bedingte schwächere, aber selbstständige Erhebung erblicken zu dürfen; es schien mir, als ob diese zweite Erhebung nur darum so rudimentär zum Ausdruck käme, weil das Herz mit einer zunächst aus unbekannter Ursache hervorgehenden gewissen Regelmässigkeit jedes zweite Mal nach einer kurzen Diastole sich weniger oder gleich stark contrahire, infolge der kurzen Diastole aber weniger Blut in die Ventrikel nachfliesse und infolge hiervon weiter die zweite Erhebung am Pulse beziehungsweise in der Zeichnung sich 1) nur sehr gering und 2) dicht an die erste, d. h. im Beginn des absteigenden Schenkels darstellen miisse. Meine Versuche bestätigten diese Annahme insofern, als ich in allen derselben unter bestimmten Bedingungen ganz constant derartige scheinbar dikrotische Wellen erhielt. In den Fällen, in denen ich Curvenzeichnungen direct vom rechten Ventrikel und von der Carotis gleichzeitig nahm, entsprachen letztere den senkrecht unter ihnen stebenden ganz ähnlichen vom Herzen. Hieraus war der Schluss berechtigt, dass die Arterienpulsfigur die Folge dieser alternirenden Contraction des Herzens selbst war, die ihrerseits besonders dann erfolgte, wenn das Herz in die zweite Contraction nach einer relativ kurzen Diastole uiberging, dabei bemerke ich, dass ich auch in den Versuchen, in denen ich die Action des Herzens palpatorisch verfolgte, mich von einer derartig abwechselnd starken und schwachen id est alternirenden Contraction des Herzens selbst iiberzeugt habe. Diese zweispitzigen Curven traten nun gewöhnlich auf, sobald ich nach Durchschneidung der Vago-sympathici die künstliche Athmung für eine kurze Zeit suspendirte; aber ich muss hervorheben, dass ich dieselben auch dann eintreten sah, sobald bei intacten Vagosympathicis allein die Athmung für einige Zeit ausgesetzt wurde.

Nach diesen vom Herzen und von der Arterie gewonnenen Curven No. 35-39 (s. S. 348), sowie nach den Ergebnissen der palpatorischen Untersuchungen kann zum mindesten für meine Untersuchungen kein Zweifel darüber bestehen, dass diese zweispitzigen

1) Die Curven sind, wie ich aus einer freundlichen Mittheilung des Verfassers erfahren, von rechts nach links zu lesen. 
scheinbar dikrotischen Pulse wirklich alternirende sind und ich glaube nicht fehlzugehen, wenn ich die von $\mathrm{H}$ of mokl gegebenen in gleichem Sinne aufzufassen wage. Die Wahrscheinlichkeit dieser meiner Auffassung wächst bei einem Vergleiche meiner Versuchsergebnisse mit analogen Untersuchungen beziehungsweise Ergebnissen derselben bei anderen Experimentatoren: Traube ${ }^{1}$ ) findet in dieser Beziehung bei curarisirten Hunden, denen er kohlensaures Natron in die Arterie gebracht, dass „unter dem Einfluss dieses Mittels und der No. 35. No. 36.
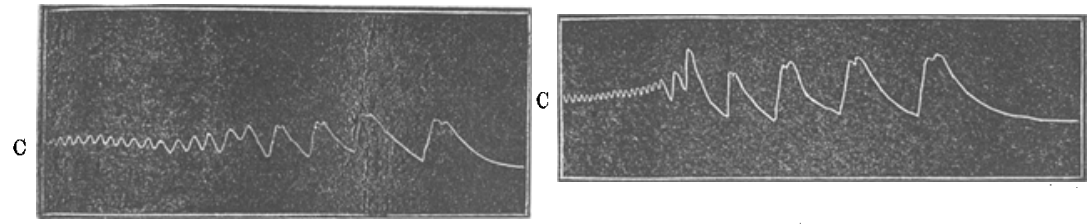

No. 37 .

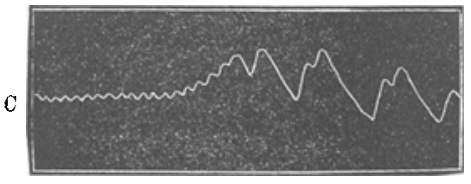

No. 38.

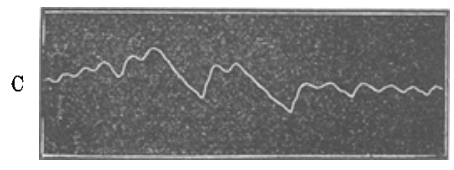

No. 39.

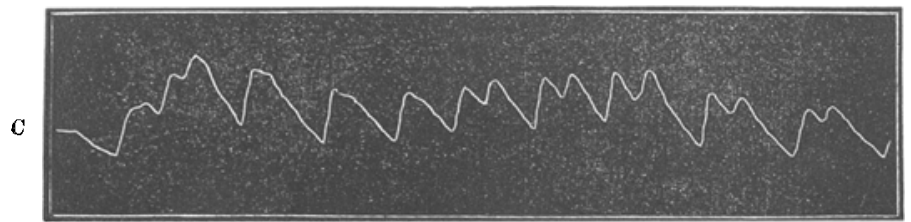

ziemlich starken Vorarawirkung sich nun die Curven von eigenthümlicher Beschaffenheit gestalten; die unter dem Einfluss der blossen Vorarawirkung ziemlich gleichschenkligen respiratorischen Elevationen werden ungleichschenklig, die Zahl der cardialen Elevationen im absteigenden Schenkel wird geringer und ausserdem zeigen sich in diesem letzteren eigenthümliche ... zweispitzige Wellen. - Diese zweispitzigen Wellen erinnern zunächst an den Pulsus dicrotus, sind jedoch von demselben .... durchaus verschieden ..... Der Unterschied des Pulsus dicrotus von den zweispitzigen Wellen bestelut darin, dass der erstere durch zwei Pulselevationen dargestellt wird, welche Einer Herzcontraction entsprechen, während bei den letzteren die beiden Elevationen durch zwei Contractionen bedingt werden, welche rasch aufeinander folgen und auf welche dann eine Pause eintritt, die länger ist, als die zwischen den Herzcontractionen der zweispitzigen Wellen liegende." Traube fand dies Phänomen zum

1) Gesanmelte Beiträge u s. w. L. Bd. Experim. Untersuchungen. 1871. 
ersten Mal bei vorarisirten Hunden, sobald nach durchschnittenen Vagis die Athmung. suspendirt wird, somit unter denselben Bedingungen, unter denen $\mathrm{H}$ ofmokl seine vermeintliche Pause des linken Ventrikels erbielt. Im weiteren Verlauf der citirten Arbeit bemerkt ubbrigens Traube, was auch ich bereits ans meinen mit den genannten uibereinstimmenden Versuchen hervorhob: „es kommen aber die zweispitzigen Wellen nicht blos nach Suspension der ktinstlichen Respiration bei durchschnittenen, sondern auch bei intacten Vagis vor", sobald die künstliche Athmung für eine bestimmte Zeit unterbrochen wird. Zur leichteren Uebersicht der vorliegenden Frage sei hier aus der citirten Arbeit Traube's ein Curvenstïck (No. 40) beigefügt.

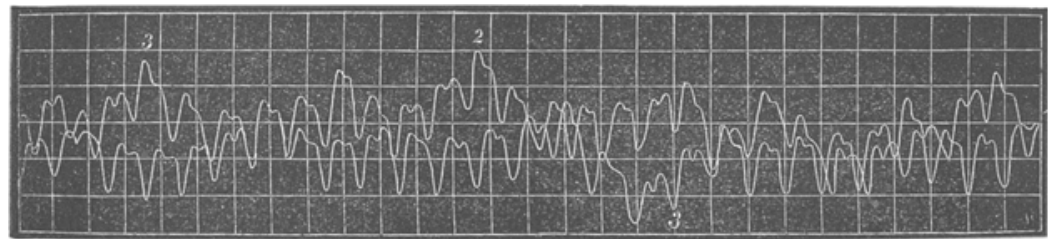

Auch Böhm veröffentlicht im 5. Bande des Pflüger'schen Archivs eine grosse Reihe Untersuchungen tiber die physiologisebe Wirkung der Digitalis und Digitalin; in Verfolg derselben an Fröschen bemerkt er .... „am Digitalinherzen, dass die Diastole in zwei getrennte Momente zerfällt, die Ausdehnungswelle wird auf der halben Höhe von einer zweiten rudimentären Systole unterbrochen, was sich in der Curve als ein exquisiter Dikrotismus zu erkennen gibt ...." Auf die Erklärung dieses Phänomens werde ich 'später einzugehen haben, bezüglich des Vergleichs der betreffenden, den vorherstehenden analogen Pulsbilder darf ich der Kürze wegen auf die Arbeit selbst verweisen.

Wenn nach dieser Auseinandersetzung die obere Curvenreihe Hofmokl's und somit der Versuch selbst uns nicht mehr eine Reihe systolischer Pausen, sondern vielmebr eine solche von alternirenden Pulsen, d. h. überhaupt keine Verminderung der Schlagzahl des linken Ventrikels zeigt, so würde jetzt nur noch die minder wichtige Frage zu beantworten sein, ob die untere, die von der Art. pulmonalis gewonnene, scheinbar so verschieden aussehende Curve wirklieh eine wesentliche, eine Deutung im obigen Sinne zulässige Verschiedenheit darbietet. In Bezug hierauf wäre, was ich bereits oben angedeutet, daran zu erinnern, dass Pulszeichnungen, die von einem dem Herzen so nahe gelegenen Gefässtheile wie die von Hauptästen der Art. pulmonalis stammen, mit solchen von entfernter gele- 
genen wie die von der Art. carotis nicht ganz mit einander zu vergleichen sind, da geringe Blutmengen, oder schwächere Herzcontractionen in dem Herzen näher gelegenen Gefässgebieten noch deutliche Pulse bewirken, die an entfernter gelegenen nur andeutungsweise oder gar nicht zur Geltung kommen. In dieser Beziehung scheint mir eine juingst von $B$ adoud I) veröffentlichte Versuchsreihe nicht ohne Interesse, aus der ich nachstehende Curve (No. 41) entnehme:

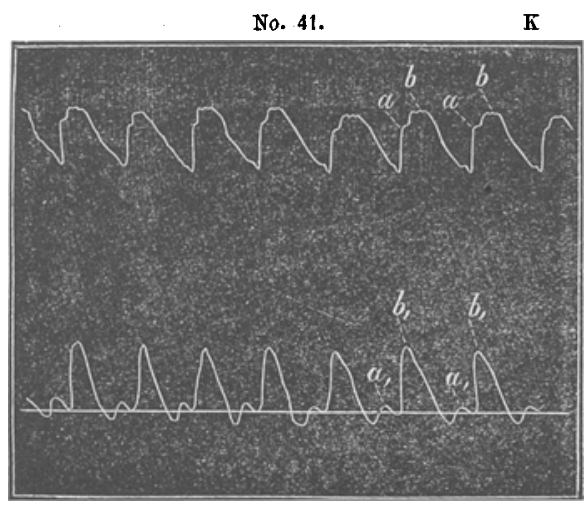

Die untere der beiden Reihen stammt vom rechten Ventrikel, die obere von der Carotis eines Hundes, der unter nahezu dieselbenVersuchsbedingungen gebracht war, wie zuvor besprochen, d. h. Curarisirung und künstliche Athmung.

An der Carotiscurve erkennen wir wiederum jene zweispitzigen Wéllen, während dieselben vom rechten Ventrikel einen nicht unwesentlich verschiedenen graphischen Ausdruck finden. Unfraglich entsprechen sich in den beiden Reihen $a$ u. $a^{\prime}$ sowie $b$ u. $b^{\prime}$ und differiren $a^{\prime} a^{\prime}$ der Lage wie der grösseren Deutlichkeit nach nicht unerheblich von $a$ a. Dass die Ursache hiervon in der oben genannten unterschiedlichen Gegend, von der die Curven gewonnen sind, zu suchen sei, scheint mir böchst wahrscheinlich. Bei einem etwaigen Versuche, die Erhebungen $a^{t} a^{t}$ als präsystolische, d. $h$. als durch Vorhofscontractionen bedingte anzusprechen, würden wir in diesem Falle Gefahr laufen, mit Rücksicht auf die zweispitzigen Wellen aus der Carotis und ihre Bedeutung bezüglich der Herzaction eine doppelte Contraction des linken Ventrikels anzunehmen. Zweitens gehen jene zweispitzigen Wellen bei niederem Blutdruck, wie es scheint in mehr flache Doppelbögen tuber, die die in Frage stehende Alternirung schwerer erkennen lassen. Von letzterem habe ich mich zum Theil schon an eigenen Versuchen uberzeugen können. No. 42.

$\mathrm{C}$

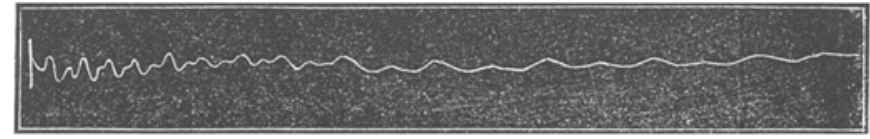

1) Ueber den Einfluss des Hirns auf den Druck in der Lungenarterie. Arbeiten aus dem physiologischen Laboratorium der Würzburger Hochschule. Von A. Fick. III. Lieferung. 1876. S. 237 ff. 
Deutlicher finden wir indess diese zweispitzigen i. e. alterniren den Pulsbögen in den von Traube gemachten Versuchen uber den Einfluss des Lungengaswechsels auf das dem Einfluss der Nervi vagi entzogene Herz. ${ }^{1}$ ) In Folgendem sei zum Vergleich eine Curvenreihe ${ }^{2}$ ) (No. 43) aus dieser Arbeit beigefügt:

No. 43 .

K

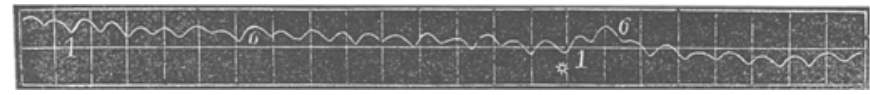

Ich deute nur kurz an, dass es sich auch hier, wie in unseren Versuchen um Durchschneidung der Vagi mit nachfolgender Athmungssuspension handelt.

Ausser $\mathrm{Hofmokl}$ glaubt, wie ich vorher bereits erwähnt, auch Klebs eine gesonderte Thätigkeit der Ventrikel in einem Falle beobachtet zu haben. Klebs versucht sogar mit Hülfe dieser Beobachtungen und der in der zuvor citirten Arbeit gegebenen sehr geistreichen Erklärung Leyden's „die secundäre Dilatation und Hypertrophie des linken Ventrikels bei Mitralinsufficienz als natïrliche Folge zu beleuchten; dabei scheint Klebs $\mathrm{Hofmokl}$ gegenüber sich den Vorgang der gesonderten Contraction so vorzustellen, dass während der rechte Ventrikel in die Systole iubergegangen, der linke in der vorherigen Diastole zunächst verbleibt. Ich vermag indess auf diese Arbeit zur Zeit nicht näher einzugehen, da der Verfasser auf die Erörterung der bezilglichen Frage, deren kurze Beantwortnng ihm sich bei seinem interessanten Versuche eben nur ganz zufällig darbot, mit "ausfïhrlichen Aufzeichnungen des Spitzenstosses und directen Beobachtungen des Herzens" noch zurückzukommen gedenkt. Aber ich glaube auch schon mit meiner Ausfiuhrung zur Genüge dargethan zu haben, dass wir es bei der in Rede stehenden eigenthümlichen und nur scheinbaren Incongruenz in der Herzaction und dem Puls keineswegs mit einer gesonderten Thätigkeit des einen oder des anderen Ventrikels sondern mit derjenigen Anomalie in der Herzarbeit beziehungsweise am Pulse zu thun haben, die man seit Traube als Pulsus alternans oder als bigeminus bezeichnet hat. Wir haben uns daher nunmehr der Frage zuzuwenden, unter welchen pathologischen Verhältnissen diese Pulsart beobachtet und wie seine Erscheinung zu erklären ist. Wenn ich mich hierbei der Bezeichnungen „Pulsus bigeminus und alternans" obne strenge Scheidung derselben bediene,

1) Ibid. S. 313 .

2) Die Angabe der Versuchsbedingungen, unter denen diese Curve gewonnen, vgl. S. 472 ibid. 
so werde ich auf die Berechtigung hierzu im letzten Theile dieser Arbeit einzugehen versuchen.

Beztiglich der ersten Frage möchte ich, um Weitläufigkeiten zu vermeiden, zunächst auf die Zusammenstellung der hier einschläglichen Fälle hinweisen, welche Riegel ${ }^{1}$ ) in seinen Beobachtungen „Zur Lehre von der Herzthätigkeit" neuerdings gegeben, wobei ich nach Maassgabe der mir zu Beobachtung gekommenen Fälle von alternirendem Pulse "die Seltenheit dieses Phänomens" nicht betonen möchte.

Auf die während der Zusammenstellung meiner Untersuchungen. noch von demselben Autor und namentlich von Fräntzel ${ }^{2}$ ) verơffentlichten, hierher gehörigen sehr interessanten Fälle komme ich zum Theil noch besonders zurtick. Zuvor sei aber noch einiger anderer von mir beobachteter und hierher gehöriger mit thunlichster Kürze Erwähnung gethan.

Der fünfte Fall meiner Beobachtungen betraf einen Arbeiter, Fr. B., 52 Jahre alt, der seit tiber 3 Jahren zum sogenannten ständigen Material unserer Klinik gehörte, die er für Wochen bis Monate als Kranker bewohnt und dann firr eine eben so lange Zeit als gebessert verlässt. Sein Leiden hat sich angeblich unter der anstrengenden Thätigkeit als Vorschläger in einer Eisengiesserei allmählich entwickelt; vor 2 Jahren sei dasselbe mit grösseren Beschwerden nach einer damals überstandenen Choleraerkrankung hervorgetreten; Herzklopfen und Schwellung der Fiusse bildeten seit der Zeit die dauernden, in ihrer In- und Extensität je nach der mehr minder grossen Thätigkeit und Anstrengung des Körpers wechselnden Klagen. Bei seiner ersten Aufnahme in die Klinik bot der tibrigens sehr robust anssehende Kranke Veränderungen dar, auf Grund deren eine idiopathische Herzhypertrophie angenommen wurde. Um die im Laufe der Jahre gemachten weitläufigen klinischen Notizen zu tubergehen, will ich nur kurz resumiren, dass sich in der genannten Zeit immer dentlicher die Zeichen einer Mitralinsufficienz und Stenose des Mitralostiums herausgebildet hatten. Unter diesen und mit den Erscheinungen einer gestörten Compensation wurde er denn auch im October vorigen Jahres in die Klinik wieder aufgenommen. Aus dem iiber ihm

1) Deutsches Archiv f. klin. Medicin. Bd. XVIII.

2) Klin. Beobachtungen von Prof. Dr. Fräntżel, Charité-Annalen 1877. S. 346. - Zu ergänzen ist hier noch der von Rosenstein, v. Ziemssen Bd. VI. S. 40 beschriebene Fall sowie die von Marey gemachte Beobachtung und Untersuchung des: Pouls périodiquement irrégulier recueilli chez l'homme. Fig. 167. p. 336 . 
geführten Journal sei nur die vom 2. Novbr. gemachte Notiz wiedergegeben: Der an den vorigen Tagen und auch sonst meist unbestimmte unregelmässige Puls hat heute einer regelmässigen Folge von hohen und niedrigen Wellen Platz gemacht, von denen letztere zuweilen verschwindend klein werden. Jede dieser Erhebungen an der Arterie entspricht der Auscultation und Palpation nach einer Herzcontraction. Die sphygmographischen Zeichnungen bestätigen die Ergebnisse der letztgenannten Untersuchung.

Ord o: Inf. digital. $1,5: 200,0-2$ stdl.

4. Novbr. Das vorgenannte Pulsphänomen blieb für Stunden des ersten und auch am folgenden Tage noch nachweisbar, ist jedoch heute unter dem Fortgebrauch vorgenannter Medication verschwunden.

Die Pulszeichnungen entsprechen im Wesentlichen denen im zweiten vorangestellten Falle, da auch hier ein Venenpuls durch die Zeichnung nachgewiesen werden konnte, ich glaube daher von einer Wiedergabe an dieser Stelle Abstand nehmen zu dürfen. Obgleich ich den Kranken bis gegen Ende December v. J. noch unter Augen behielt, habe ich trotz wiederholt auftretender Pulsirregularitäten diese nahezu regelmässige Anomalie bei ihm nicht wieder gefunden.

Ebenso voribergehend beobachtete ich dieselbe im folgenden sechsten Falle. Frau Sch. K., 49 Jahre alt, leidet seit angeblich 25 Jahren an wiederkehrendem Rheumatismus; Beschwerden, die auf eine Mitbetheiligung des Herzens hindeuten, scheinen nach den anamnestischen Angaben, vor etwa 16 Jahren zuerst aufgetreten zu sein. Es handelt sich um eine mittelgrosse bleiche und im Gesicht etwas cyanotisch aussehende Patientin in mässig gutem Ernährungszustande. Die Herzdämpfung beginnt an der dritten Rippe, wird an der nächsten intensiv, der Spitzenstoss im sechsten Intercostalraum 1 Zoll jenseits der Linea mammillaris, verbreitert und hebend sicht- und fühlbar; die nach der linken Sehulter zu wenig convexe Linie, welche diese Stelle mit der $1^{1 / 2}$ Zoll vom linken Sternalrand entfernt beginnenden oberen Grenze verbindet, stellt die äusserste linke Begrenzung des Herzens dar. Nach rechts hin lässt sich die Herzdämpfung durch eine schräg verlaufende Linie andeuten, die am Ansatz der knorpligen dritten Rippe an dem rechten Sternalrand beginnt und die vierte und fünfte Rippe 1/2 Zoll rom rechten Sternalrand entfernt schneidet. Die Palpation ergibt an der Spitze ein kurzes diastolisches Frémissement, dem bei der Auscultation ein längeres diastolisches Geräusch entspricht, in der Systole wird dagegen ein lauter, wie es scheint, etwas gespaltener Ton hörbar. Dasselbe am unteren Theil des Sternums, nur etwas schwächer, 
desgleichen, aber lauter am Ansatz der dritten Rippe links vom Sternum; im zweiten Intercostalraum rechts ein dumpfer systolischer Ton, im zweiten Intercostalraum links zwei laute Töne, von denen der zweite accentuirter und von einem leisen sausenden Geräusche begleitet scheint; das vom Ansatz der dritten Rippe links vom Sternum zu börende Geräusch ist dem Timbre nach sehr verschieden von dem an der Spitze, das letztere erscheint je mehr sich in der Zeit der systolischen Herzphase nähernd, um so deutlicher und in der Mitte wie getheilt, das erstere an der Basis dagegen continuirlich. Die Untersuchung des Abdomens ergibt einen die Nabellinie erreichenden Lebertumor.

22. Juli. Der früher sehr beschleunigte Puls ist seit gestern unter dem Gebrauch von Digitalis bis auf 40-60 heruntergegangen.

Bei dem zufälligen Besuch der Kranken durch den Untersuchenden ausserhalb der gewöhnlichen Visitenzeit erschrak dieselbe, wurde blass, die Herzaction beschleunigt, letztere zeichnete sich dadurch aus, dass bald zwei Spitzenstösse schnell aufeinander folgten und durch eine längere diastolische Pause von den nächsten zwei getrennt blieben, bald aber drei Herzstösse dieselbe kurze Aufeinanderfolge mit einer gleich verlängerten Pause hinter ihnen auftraten. Die dazu gehörigen Pulse zeigten dem entsprechend die gewöhnlichen Charaktere des einfach alternirenden oder des doppelten, $d . h$. des nach Riegel genannten Pulsus trigeminus. Seit der Zeit vermochte ich diese eigenthtimliche Herzaction durch forcirte Körperbewegungen der Kranken in- oder ausserhalb des Bettes so oft hervorzurufen, als ich zum Nachweis derselben durch sphygmographische Curven bedurfte, wobei ich ganz unbestimmt den einen Tag rein alternirende, das andere Mal solche des Pulsus trigeminus bekam.

Das siebente Mal beobachtete ich diese Erscheinung bei einem 20 jährigen jungen Kaufmanne K., der angeblich mit kurzen Unterbrechungen seit drei Jahren an rheumatischen Beschwerden leidet und aus einer Familie stammt, in der Herzkrankheiten wiederholt vorgekommen sind (Vater und eine Schwester). Die subjectiven Klagen des Kranken bezogen sich auf Herzklopfen und Athemnoth, die namentlich beim Treppensteigen und nach rascheren Bewegungen aufzutreten pflegen. Als ich ihn das erste Mal untersuchte, fiel mir gleich die eigenthümliche Herzaction auf, die das bereits wiederholt geschilderte Verhältniss derselben zum Pulse resp. des Pulsus alternans darbot; die Herzaction war dabei sehr beschleunigt, ich verordnete ein Digitalisinfus von 1,0:200,0 2 stdl. Nach 2 Tagen (16. Januar) erschien der Kranke wieder bei mir, und die von 
diesem Tage gezeichneten Curven ergaben folgende interessante Veränderung in der Herzaction und am Pulse.

Ich bemerke in Bezug auf diese Curven (No. 44 u. 45), von denen die erstere von der Radialis, die zweite rom Herzen genommen ist, dass dieselbe, wie leicht ersichtlich, doppelt alternirend und als ähnlich der von Riegel als Pulsus trigeminus gelten darf. Am 20. Januar, nachdem der Kranke noch eine Flasche von obigem Digitalisinfus ver-

No. 44 .

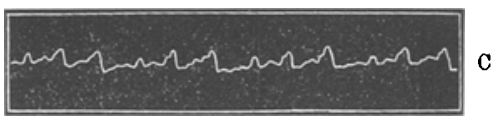

No. 45.

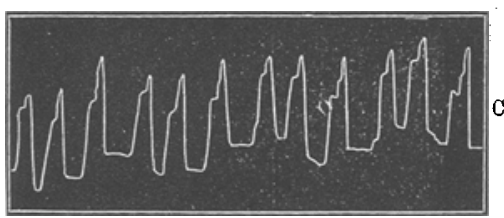
braucht hatte, sah ieh ihn bis jetzt zum letzten Male wieder. Das Herzklopfen hatte nachgelassen, ,das Gefühl, als ob das Herz häufig jeden zweiten oder dritten Schlag stillstehe" aufgehört. Aus den über den Kranken mir vorliegenden Notizen hebe ich nur hervor, dass derselbe ausserordentlich kräftig aussah und ausser den genannten Beschwerden über nichts hier Wesentliches zu klagen hatte. Die Percussion des Herzens ergab eine mässige Verbreiterung der deutlichen Herzdämpfung nach rechts, einen deutlichen im fiunften Intercostalraum in der Lin. mammillaris sicht- und fühlbaren Spitzenstoss, hier ein leises systolisches Geräusch, einen zweiten etwas dumpfen Ton, zweiter Ton über der Pulmonalis exquisit klappend, sonst keine nennenswerthe Abnormität am Herzen zu constatiren. Die von diesem Tage rom Kranken entnommenen Curven (No. 46 u. 47) zeigen eine im Ganzen regelmässige Schlagfolge am Herzen und am Pulse.

Das achte Mal hatte ich bei einem Emphysematiker mit ganz auffallend starker Cyanose des Gesichts, der Füsse und der Hände - es war ein 50 jühriger Fischer L. S. - bei dem am Herzen nichts Besonderes nachweisbar war, Gelegenheit während seines mehrwöchentlichen Aufenthaltes in der Klinik häufig Tage lang und unabhängig von etwaigen Digitalisgaben einen Pulsus alternans zu beobachten; derselbe unterschied sich von den früheren No. 46 .

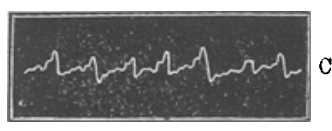
No. 47

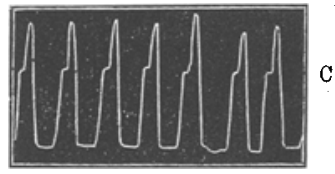
durchaus in Nichts. Die beiden folgenden Curven (No. 48 u. 49) ergaben den Befund einer neunten und zehnten Beobachtung deren Zeichnungen ich hier wiedergebe, weil ich später an sie noch anzuknüpfen haben werde. Die obere ist von einem 27 jährigen Maurer, P. K., die derselbe während fast 3 Tagen im Beginn der ReconArchiv fur experiment. Pathologie a. Pharmakologie. VIr. Bd. 
valescenz nach einem mittelschweren Typhus exanthematicus darbot; die untere stammt von einem 46 jährigen Sattler, C. F., der an den Erscheinungen der Tabes dorsualis in unserer Klinik behandelt wurde. Während der 3 Wochen, in denen ich ihn zu beobachten Gelegenbeit hatte, war diese Pulsart fast constant.

No. 48 u. 49 .

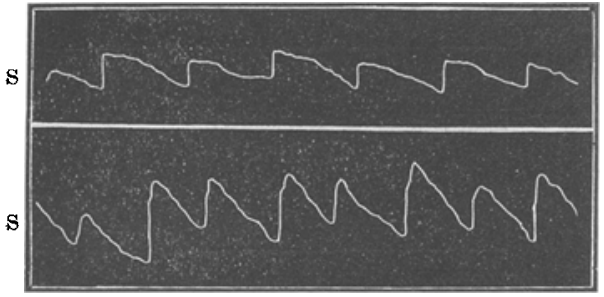

Es sei noch bezulglich derselben bemerkt, dass am Herzen in beiden Fällen keine Anomalie nachzuweisen und dass zur Darreichung von Digitalis niemals Veranlassung gewesen war.

Ausser den genannten zehn Fällen 1) habe ich diese Pulsart ganz vorübergehend noch in zwei von croupöser Pneumonie und zwar vor der Krisis gesehen; leider waren beides Potatoren, die in ihren Delirien nicht zur Ruhe zu bringen waren, die eine sphygmographische Pulsaufnahme hätten ermöglichen können. Obwohl ich fortdauernd seitdem auf jede Pulsanomalie geachtet, habe ich bei den folgenden ziemlich zahlreichen Pneumonikern unserer Station die in Rede stehende nicht mehr gefunden. Ich möchte daher bei der Gelegenheit auf eine andere sonst bekannte Erscheinung am Puls hinzuweisen mir erlauben, die bei blosser Palpation vielleicht zu einer Verwechselung mit dem Pulsus alternans führen kann: Wir wissen, dass unter dem Einfluss der Inspiration und namentlich der forcirten der Puls kleiner erscheint; bei sehr frequenter Respiration, bei der die Anzahl der Inspirationen zum Pulse in das Verhältniss von 1:2 träte, könnte leicht ein Puls auf die In- der nächstfolgende genau auf die Exspiration fallen; unter solchen Verhältnissen würde der zufühlende Finger den ersteren niedriger, den zweiten höher, beziehungsweise umgekehrt fühlen und beurtheilen.

No. 51 .

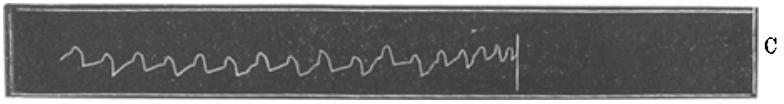

Die Radialiscurve No. 51 stammt zwar von

1) Augenblicklich habe ich Gelegenheit einen Fall von Bulbärparalyse mit No. 50. fast anhaltendem Pulsus alternans $\mathbf{z u}$ beobachten; c die Curve (No. 50) ist von urrorrarrarror der Radialis dieses Patienten gewonnen. 
No. 52.

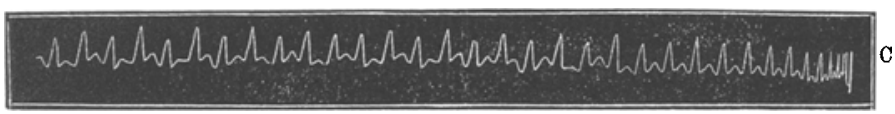

einer an einem Vitium cordis complicatum leidenden Patientin, die aber nur obige durch die vermehrte Respiration beeinflusste PuIserscheinung vorübergehend zeigte. 70 Pulse kamen in diesem Falle auf ca. 30-36 Respirationen, die tiefer stehenden, für den palpirenden Finger als kleiner erschienenen Erhebungen fielen genau mit der Inspiration zusammen. Die Curve No. 52 ist von einem Typhuskranken genommen; die ersten 11 Pulse dieser Reihe sind bei gewöhnlicher, die folgenden bei einer im vorgenannten Verbältniss vermehrten Respiration gezeichnet. Die Berücksichtigung dieses Einflusses der Respirationen wird sicher jede Verwechselung im vorigen Sinne ausschliessen und dies vielleicht um so eher, als die Respiration auf den eigentlichen Pulsus alternans umgekehrt $\mathrm{zu}$ wirken scheint. ${ }^{1}$ )

Es würde mich zu weit führen, wollte ich nunmehr meine Beobachtungen in ihren Erscheinungen mit den in der Literatur niedergelegten vergleichsweise besprechen; ebenso möchte ich der Kürze wegen von der Entwicklung der Diagnose bezuiglich der ersteren abstehen, da eine etwas genauere Durchsicht der einzelnen Krankengeschichten dieselbe leicht ergibt. Ich begnüge mich in der vorherigen Beziehung nur kurz hervorzuheben, dass unter dem Einfluss von Digitalis in dem vierten meiner Fälle der Pulsus alternans ebenso hervorgetreten zu sein scheint, wie er unter der Einwirkung desselben Mittels im fünften und siebenten sicher verschwand; dass zweitens der erste Fall dadurch ganz ausgezeichnet ist, dass bei demselben jetzt 1 Jahr hindurch der Pulsus alternans bei einem relativ ausserordentlich guten Befinden der betreffenden Person und ohne Digitalisbeeinflussung dauernd fortbesteht. Ueberblicken wir nun die Krankheitsfälle, so finden wir, dass das in Rede stehende Pulsphänomen

1) Wenigstens habe ich in einem Falle von Mitralinsufficienz und -Stenose die kleinere zweite Pulserhebung in der Inspiration constant wachsen gefühlt. - Der obere Theil der Respirationscurve ist um Raum zu ersparen, abgeschnitten, die absteigende und mehr horizontal verlaufende Linie derselben zeigt die Inspirations -, die aufsteigend bis fast zur nächsten absteigenden die Exspirationsphase an. Es muss natürlich weiteren Prüfungen vorbehalten bleiben, ob diese Erscheinung eine constante sei oder nicht.

No. 51 a.

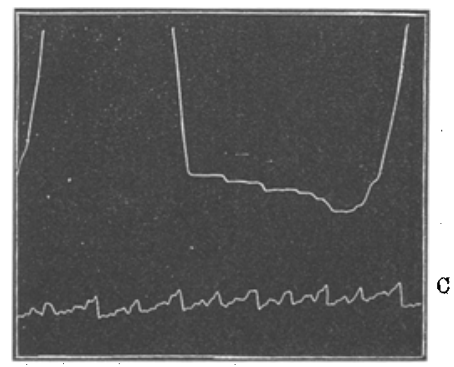


unter den allerverschiedensten pathologischen Zuständen beobachtet wurde (wobei ich noch einer Beobachtung Riegel's ${ }^{1}$ ) bei mehreren rechtsseitigen Gehirnerkrankungen ergänzend Erwähnung thun möchte). Hieraus geht hervor, dass diese Erscheinung diagnostisch mit Sicherheit kaum wird verwerthet werden können, wir wollen uns jetat daher der Beantwortung der Frage zuwenden, wie wir uns etwa die Entstehung dieses Pulses zu denken haben. Aus dem oben genannten Grunde wird man kaum erwarten dürfen, seine Entstehung auf eine gemeinsame Ursache zurückführen zu können. Bei der Annahme verschiedener Ursachen aber wäre es möglich, dass 1) Hindernisse und auch hier schon periodisch wechselnde im Mechanismus des Circulationsapparates bestunden, 2) könnte aus irgend welchen Ursachen eine Ungleichbeit in der Kraftleistung des Herzens abwechselnd ungleiche Pulse erzeugen.

In die erste Kategorie gehören die relatir häufig beobachteten Fälle von Pulsus alternans bei Mitralfehlern und die zwei bei Aortenaneurysmen, der eine dieser Fälle ist in den letzten Charité-Annalen von Fräntzel veröffentlicht; es handelte sich dabei um „ein Aneurysma der aufsteigenden Aorta mit gleichzeitiger Insufficienz der Aortenklappen", der zweite ist der von mir beobachtete vorangestellte dritte Fall bei einem 40 jährigen-Lehrer. Für diese beiden Arten der Störung der mechanischen Verhältnisse des Circulationsapparates ist folgendes Raisonnement wohl gestattet: Bei Mitralfehlern ist das rechte Herz mit Blut überfüllt und der linke Vorhof vermag, wenn Stenosirungen des linken Atrioventricularostiums bestehen, den linken Ventrikel nur mit Mühe mit Blut zu bespeisen. Bei genuigend ausgesprochenen Diastolen wird der linke Ventrikel eine relativ genügende Blutmenge aus dem Vorhof erhalten und in das Aortensystem schleudern können; tritt aber der Ventrikel in einem zur Stenose verhältnissmässig zu raschem Tempo aus seiner Diastole heraus, d. h. kehrt die Systole des Ventrikels (sei es in Folge entzundlicher Reizung des Herzmuskels, sei es unter dem Einflusse fieberhafter oder psychischer Erregung oder in Folge einer venösen oder sonstig toxischen Beschaffenheit des Blutes oder sonstwie vorübergehend erregten Herzens) schneller zuriick, so hat in der kürzeren Zeit in den linken Ventrikel eine zu einem vollen Pulse ausreichende Blutmenge nicht gelangen können. Die Folge hiervon wird ein verschieden kleinerer Puls sein und dieser kleinere Puls wird, da die Arteriensystole zunächst unabhängig ist von einer zu-

1) Zur Pulstehre. Deutsch. Arch. f. klin. Med. Bd. XVIII. 
fällig schneller eingetretenen zweiten Systole des Herzens, an irgend einer Stelle des absteigenden Schenkels dieser primären grösseren Pulswelle erscheinen müssen. Ferner wird die Annäherung dieser kleineren secundären Welle an die primäre eine um so engere sein, je schneller die beiden Systolen des Herzens auf einander gefolgt waren und eine um so entferntere bei der entgegengesetzten Folge, d. h. im letzteren Falle wird die secundäre Welle kurz vor der nächsten primären grösseren Erhebung erscheinen und beiläufig so der Pulsus bigeminus sich als alternans präsentiren. Für das Letztgesagte Belege mit Pulsbildern zu geben halte ich kaum für nöthig, da auch von anderer Seite bereits die Möglichkeit des Ueberganges des einen in die andere Pulsart betont ist. Es steht kurz gesagt, um bekanntere Pulserscheinungen zum Vergleiche noch hier zu erwähnen, der Pulsus bigeminus zum alternans in demselben Verhältniss nach meiner Erklärung wie der Pulsus dicrotus zum Pulsus capricans, d. h. je nachdem die dikrotische Welle höher oben i. e. näher der primären Welle oder tiefer unten, näher dem folgenden Pulse, ist, ist derselbe ein rein dikrotischer oder ziegensprungähnlicher. Diese Bedingungen für die mangelhafte Füllung des linken Ventrikels bei dem supponirten Herzfehler werden ferner um so gïnstigere sein, wenn zufällig noch eine relative Insufficienz der Tricuspidalklappen dabei besteht; denn nun wird (vielleicht durch die Lage des Körpers und im weiteren Gefolge durch die hierdurch gegebene Richtung der Ostien) während der Contraction des Herzens das Blut vom rechten Ventrikel aus mehr in die Gebiete der Vv. cavae getrieben werden können als in die Art. pulmonalis, von deren jeweiliger Füllung aber schliesslich der Blutgehalt des linken Vorhofes i. e. des linken Ventrikels und des Arteriensystems abhängig ist. Aus einem bestehenden Venenpulse bei einer gleichzeitig mehr minder angedeuteten Arterienerhebung - und um solche handelt es sich ja in den Fällen von doppelter Herzaction oder Pulsus alternans, wie ich nachgewiesen, allgemein - können wir somit nur den Schluss ziehen, dass trotz der gemeinschaftlichen Arbeit beider Herztheile in die Arterie zeitweise kein oder wenig Blut einströme, weil durch die Tricuspidalinsufficienz das Blut aus dem rechten Ventrikel zum Theil in die Vena cava regurgitire, statt in die Art. pulmonalis einzutreten. Auffallend bliebe bei diesem Circulationsphänomen nur die eigenthümliche rhythmische Folge im Füllungswechsel, der alternirende Puls. Aber diese Abhängigkeit des Pulses in der Arterie bezüglich seiner Völle vom jeweiligen Abnehmen des Venenpulses demonstriren $u$. A. meine ersten beiden 
Krankheitsfälle, wie ich glaube, zur Genüge; aber ich möchte indess hier noch eines anderen Falles Erwähnung thun, indem ich diese Erscheinung noch deutlicher habe sehen können. Es handelte sich dabei um einen an Emphysem und Concretio pericardii leidenden Kranken, bei dem nach geringen Morphiumgaben 2 Tage vor seinem Tode die Respiration auffallend verlangsamt wurde. In der Minute erfolgten 3-4 Athmungen und vielleicht unter dem Einfluss dieser beobachtete ich einen Pulsus myurus, bald ascendens bald descendens, während der bestehende Venenpuls sich umgekehrt verhielt. Die im Ganzen undeutlichen Herztöne schienen sich bezüglich ihrer Deutlichkeit im Sinne des Venenpulses zu verhalten: wenn somit am Herzen - der Spitzenstoss war kaum fühlbar - drei oder vier Töne mit abnehmender Stärke gehört wurden, trat an der Vene ein Pulsus myurus descendens, an der Arterie ein ascendens auf und umgekehrt, was doch nichts Anderes bedeutet, als dass unter den drei oder vier an Kraft abnehmenden Herzcontractionen die relativ kräftigere nur deshalb in der Arterie einen relativ kleineren Puls erzielte, weil zur selben Zeit ein Theil des Blutes in die Körpervenen zurücktrat und umgekehrt eine schwache Herzcontraction einen relativ volleren Puls zu Stande brachte, sobald mit Abnahme des Venenpulses mehr Blut nach dem linken Herzen hintiber gelangte; ähnlich gestalten sich wohl auch die Verhältnisse bei Mitralklappeninsufficienz oder bei einer Combination dieser mit einer Stenose des Mitralostiums. Wie aber haben wir uns den Mechanismus in den von Fräntzel und von mir beobachteten Fällen von Pulsus alternans bei Aneurysmen zu denken? Zur Beantwortung sei hier vorausgeschickt, dass beide Fälle eine erhebliche Verlangsamung im Pulse zeigten, der erstere 56, der letztere $36-40$ in der Minute. In dieser Pulsverlangsamung dürfen wir vielleicht den Ausdruck dafür erblicken, dass das Herz unter solchen Bedingungen nicht eher zu einer neuen Contraction herantritt, bis die grosse aus dem Aneurysma in das Arteriensystem auf einem Male eintretende Blutmenge sich allmählich und gleichmässig in der Peripherie vertheilt hat. Dass dem so ist, können wir durch die Palpation der Arterien erkennen, erkennen wir aber besonders in dem vom sonstigen abweichenden Capillarpulse, auf den ich an einer anderen Stelle näher einzugehen gedenke. Wird nun das Herz aus einer der vorber genannten Ursachen zu einer schnelleren Contraction angeregt - in meinem Fall durch Körperbewegung - so hat bis zur zweiten überraschten Contraction noch keine gentigende Blutmenge von der $\mathrm{Pe}$ ripherie her zum Herzen zurückkehren können und was der linke 
Ventrikel unter solchen Verhältnissen vom Vorhof bekommt und dem Arteriensystem geben kann, ist trotz seiner gentigenden Anstrengung eben nur ein Rudiment von Puls, der sich bezitglich seiner Lage zur vorherigen und zur folgenden grösseren Welle gerade so verhalten wird, wie in der obigen in dieser Beziehung geführten Auseinandersetzung.

Als zweite Entstehungsursache des Pulsus alternans können wir uns, wie vorhin angedeutet, vorstellen, dass das Herz sich abwechselnd stark und sehwach contrahirt ohne dass sonst mechanische Hindernisse für den Bluteintritt oder Blutaustritt vorliegen. Dass derlei aber schon unter den eben genannten Verbältnissen vorkommt, das lehren die verschiedentlich meinen Beobachtungen beigesetzten Hèrzcurven, in denen man bei genauerer Betrachtung entsprechend den grösseren und kleineren Wellen am Pulse höhere und niedrigere Wellen als Zeichen des stärkeren und schwächeren Herzstosses wiederholt wiederfindet. Für einen Theil dieser Fälle, sei es dass Herzfehler vorliegen oder nicht, könnten wir vielleicht mit $\mathrm{Traube}$ eine bestehende Lähmung des spinalen and eine Erregung des cardialen Theiles des Herzhemmungssystems annehmen, wie z. B. für die Riegel'schen Erkrankungen des Gehirns, für den Henoch'schen Fall von Diphtheritis; bei diesen Erkrankungen sehen wir ja nicht selten Pulsbeschleunigung mit Pulsverlangsamungen abwechseln. ${ }^{1}$ ) Aber für die überwiegend grössere Anzahl der Fälle ist folgende Ueberlegung vielleicht gestattet: Besteht in Folge einer Schwächung des Körpers überhaupt (Reconvalescenz, Fieber, Anämie, Kachexie) gleichzeitig eine schwächere Herzthätigkeit (Verfettung) und wird an einem solchen Organismus eine Mehrleistung, z. B. nur in der Bewegung des Körpers (6. Fall meiner Beobachtungen) oder irgend welche andere Erregung des Körpers gesetzt, so reagirt das Herz nach unserer täglichen Erfahrung am Krankenbett allgemein zunächst häufig mit einer unregelmässigen Action. Auf diese mannigfachen Arythmieen hier näher einzugehen, glaube ich der Kürze wegen verzichten zu dürfen und dies um so mehr, als dieser Gegen-

1) So habe ich noch vor wenigen Wochen einen Fall von Urämie bei einem 6 jährigen Knaben anf der hiesigen medicinischen Klinik beobachten können, bei dem die Herzaction sub fnem vitae bald zwischen 26 and 30 Schlägen, bald zwischen 80 und 120 schwankte. Hierin liegt vielleicht jener von Tra ube präsumirte Kampf der beiden Centren, aber in einer etwas anderen Weise ausgeprägt; in diesem Kampfe könnten in dem einen oder in dem anderen Falle die beiden Centren sich für eine Zeit das Gleichgewicht halten und so eine Action des Herzens auslösen, die der hier in Frage kommenden vollständig entspräche. 
stand erst neuerdings von Nothnagel ausführlicher behandelt worden ist. Nur zwei Beispiele eigener Beobachtung seien hier zum besseren Verständnisse gestattet. Unter den eben genannten Verhältnissen sehen wir bald blos den einen, bald blos den anderen Herzschlag ausfallen und zwar bei demselben Individuum verschieden zu verschiedenen Zeiten.

No. $52 \mathrm{~b}$.

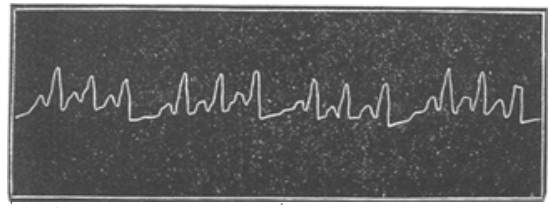

No. $5 \%$

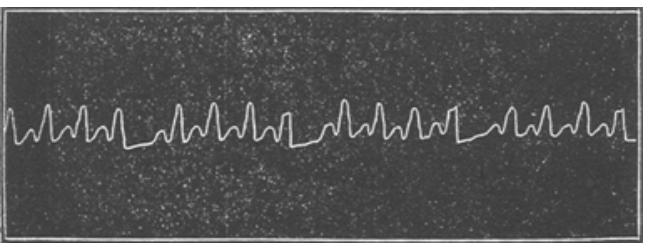

Die Curven No. 52 b u. 53 stammen von einem an einem rechtsseitigen Empyem Ieidenden Patienten, der ohne nachweisbare Ursache 2 Tage vor der Operation futr Stunden bald die eine bald die andere Art des regelmässig intermittirenden Pulses zeigte, cintermittirend weil zur selben Zeit am Herzen ein schwacher Ton hörbar war. Ein anderer

No. 54.

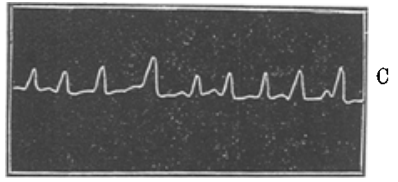

No. Бอ.

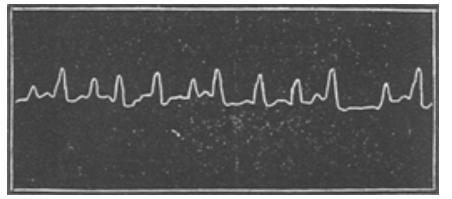

No. 56 .

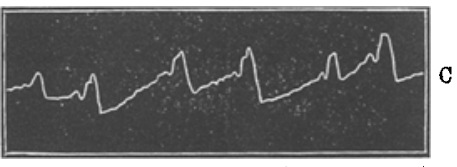

Kranker mit hochgradigem Emphysema pulmonum variirte in folgendem Pulsrhythmus.

Wir erkennen in diesen drei Arten einen ganz bestimmten Pulstypus; der erstere (No. 54) zeigt einen regelmässigen Pulsus myurus, bei dem beiläufig die zugehörigen Herztöne $c$ in einem gleichen Verhältniss an Stärke abnahmen u. s. w.; in No. 55 wechselt ein alternirender Puls ab mit einem kurzeren Pulsus myurus, im dritten (No. 56) ist ein fast reiner Pulsus alternans gegeben. Hinzugefügt sei noch, dass wie im obigen Falle ron Empyem die Operation in diesem letzteren Digitalis den irregulären Puls in einen regulären umgestaltete. Mit Berücksichtigung nur dieser zweier Beispiele erinnern wir uns der nicht seltenen Beobachtung, dass unter den mannigfachen Pulsirregularitäten eine grosse Zahl gewissermaassen regelmässiger Arythmieen vorkommt, denen wir keineswegs eine so grosse Bedeutung beilegen, wie dies zum Theil für den Pulsus 
alternans geschieht. Es wird dies um so auffälliger, wenn wir den letzteren gar aus dem ersteren direct hervorgehen sehen. Hiermit sei nur der Hinweis darauf gestattet, dass der Pulsus alternans für viele Fälle absolut keine specifische Bedeutung habe, die etwaige Prognose nicht mehr und nicht minder wie jede andere Pulsirregularität beeinflusse; dass er zweitens da, wo die Traube'sche Theorie vielleicht eine berechtigte Anwendung finden könnte - bei Diphtheritis, bei Gehirnerkrankungen, bei Erkrankungen des Centralnervensystems iuberhaupt - wohl auch kaum mehr zu bedeuten habe, als die abwechselnd unter solchen Verhältnissen erscheinende abnorme Pulsbeschleunigung und Pulsverlangsamung. Drittens für die Fälle, in denen als Ursache ein mechanisches Hinderniss im Circulationsapparat gegeben ist, kann der Pulsus alternans dauernd und als relativ normaler auftreten, wie dies der erste Fall meiner Beobachtungen lehrt und vorübergehend mit derselben allgemeinen Bedeutung wie unter 1. Ich möchte als viertens noch resumiren, dass auch nach meinen Beobachtungen der Pulsus alternans 1) unbeeinflusst von Digitalisgebrauch und 2) nach demselben ebenso hervorteten wie versehwinden kann, analog der gewöhnlichen Finwirkung dieses Mittels, unter dem ja der Puls bezilglich der Frequenz gleichfalls nach der einen und nach der anderen Richtung sich verändern kann; dass endlich fünftens die gesonderte Action des rechten Ventrikels nach den von mir gegebenen, dem Anschein nach exquisiten Krankheitsfällen, sowie nach meinen experimentellen Untersuchungen zunächst als mindestens nicht erwiesen zu betrachten ist. $\left.{ }^{1}\right)$

Ich habe mich in der vorliegenden Arbeit für die in Frage kommenden abwechselnd hohen und niederen Pulswellen bisher fast

1) Bei meinen fortgesetzten Beobachtungen des in Rede stehenden Pulses ist es mir sehr wahrscheinlich geworden, dass derselbe auch dadurch entstehen könne, dass die Vorhöfe jedes zweite Mal sich schwächer oder gar nicht contrahiren. Die Curve No. 57 stammt vom Herzstosse

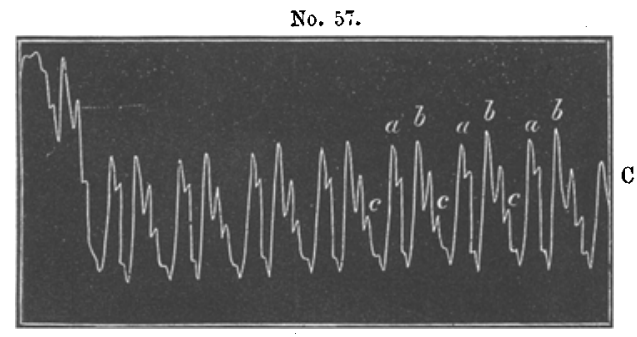
eines Kranken mit Pulsus alternans, bei dem übrigens die zweite kleinere Welle von der Arterie zuweilen ganz fehlte. Die letzteren nun fielen zusammen mit den Herzerhebungen $a a a$, denen die bei $b b b$ auch schon für die Palpation deutlich kenntlich gewesenen Vorhofscontractionen $c c c$ für Gefühl und Zeichnung fehlten. 
stets der Bezeichnung „Pulsus alternans" bedient, obwohl eine genauere Beobachtung der einzelnen zeigen dürfte, dass ihr Grundeharakter nicht durchgehends derselbe, oder richtiger, dass die meisten eigentlich Pulsus bigemini gewesen. Riegel hat in seinen wiederholt citirten Veröffentlichungen diesen Unterschied namentlich betont und es erübrigt daher noch zum Schluss auf die Frage nach dem Nutzen und der Berechtigung dieser Unterscheidung mit einigen Worten einzugehen: Tra u be ${ }^{1}$ ) differenzirt diese beiden verwandten Pulsarten in folgender Weise: „das Wesen des Pulsus bigeminus besteht darin, dass auf je zwei Pulse, die im Aortensystem entstehen, eine längere Pause folgt..... mit diesem hat der Pulsus alternans das gemein, dass der normale Rhythmus nicht durch eine Arhythmie, sondern durch einen fremdartigen Rhythmus ersetzt wird, bei welchem je zwei aufeinander folgende Pulse in näherer Beziehung zu einander stehen; es handelt sich um eine Aufeinanderfolge hoher und niedriger Pulse, die in der Art vor sich geht, dass regelmässig auf einen hohen ein niedriger Puls folgt und dass dieser niedrige Puls von dem nächstfolgenden hohen durch eine kürzere Pause geschieden ist als von dem hohen Pulse, der ihm vorhergeht." Mit Anerkennung dieser von Traube gegebenen Unterscheiduing hebt Riegel2) beztiglich des Pulsus alternans noch hervor: dass hier abwechselnd hohe und niedrige Pulse aufeinander folgen, die beide von der gleichen Basis ausgehen, während die Gipfelpunkte in verschiedener Höhe liegen. „Mit Zugrundelegung dieser Verhältnisse müssen die friber mitgetheilten Pulse als echter Pulsus bigeminus bezeichnet werden $u$. s. w."

Ich habe vorher bereits gezeigt, dass die grössere oder geringere Annäherung der kleinen Pulswelle an die vorhergehende und folgende höhere von untergeordneter Bedeutung ist, dass in dieser Beziehung Uebergänge vorkommen können; dasselbe gilt nun auch fur das von Riegel hervorgehobene Unterscheidungsmerkmal. Obzwar von beiden Autoren die innere Verwandtschaft beider Pulsarten zugestanden wird, meint Riegel dennoch, dass als rein alternirender Puls nur der zu bezeichnen sei, dessen Basen in eine gerade Linie fallen. Betrachten wir aber die Fälle, auf die hin Riegel diese Trennung wïnscht - es sind das der von Traube und Stricker beschriebene - so sehen wir, dass diese Bedingungen an den von den genannten Autoren gegebenen Curven keines. wegs erfüllt werden; eine durch die Fusspunkte der hohen Pulswelle

1) Vgl. Berliner klinische Wochenschr. Jahrg. 1872. No. 16. S. 185.

2) Deutsch. Arch. f. klin. Medicin. Bd. XVIII. S. 507. 
gelegte gerade Linie zeigt uns, dass die Basen der kleineren Pulswellen durchweg, wenn auch nur etwas, höher stehen und nur so tief scheinen, weil die Zeichnungen im Ganzen klein sind. Bei einiger Berücksichtigung der Curvenzeichnungen meines ersten Falles ist dieser Wechsel in der Lage der kleinen Welle, der allerdings leicht zu obiger Verwechselung fuhren kann, erkenntlich und es beruht diese Erscheinung auf Druckverhältnissen in der Feder des Sphygmographen, auf einer dickeren oder dünneren Beschaffenheit der Weichtheile des Armes u. s. w. Nichts destoweniger besteht die Beobachtung Ri e gel's zu Recht, dass nämlich alternirende Pulse vorkommen, und zwar gleichgipflige und gleichbasige; von Jetzteren sind bisher, so weit mir bekannt, noch keine veröffentlicht, ausser den von mir bei einem Typhusreconvalescenten im Falle 9 (No. 48) und den in der Anmerkung notirten Fall 11 (No. 50) beobachteten, auf deren beigesetzte Curven ich deshalb hier verweisen möchte; gleichzeitig bemerke ich, dass ich dieselben vereint mit gleichgipfligen, alternirenden Pulsen im zehnten Fall (No. 49) und im elften Fall (No. 50), wie die betreffenden Curven zeigen, habe beobachten können. Zur Vervollständigung des Gesagten muss ich indess hinzufügen, dass eine der in Rede stehenden ähnliche Pulsart auch von Riegel ${ }^{1}$ ) selbst beobachtet und veröffentlicht ist, die er als eine Unterart des Pulsus alternans bezeichnet und die darin besteht, dass ein hoher und ein niederer, hierauf ein höherer, der aber niedriger ist, als der erste, und endlich viertens ein rudimentärer Puls, die sämmtlich von gleicher Basis ausgehen, rhythmisch anfeinander folgen. Riegel schlägt vor, diese Art als Pulsus alternans duplicatus zu benennen; dem gegenuiber ist es mir von hohem Interesse an dieser Stelle einen nach Riegel als echten Pulsus bigeminus anzusehenden Puls zu veröffentlichen, der in fast gleichem Sinne wie der vorherige, d. h. als Pulsus bigeminas duplicatus sich verhält (in dem hier die kleineren Wellen in je 4 Pulsen unter sich wieder alterniren), und somit gleichzeitig geeignet ist, von Neuem die grosse Verwandtschaft beider Pulsphänomene zn documentiren. Es stammt diese Curve (No. $58 \mathrm{a}-58$ b) von dem ersten der vorangestellten No. $58 \mathrm{a}$.

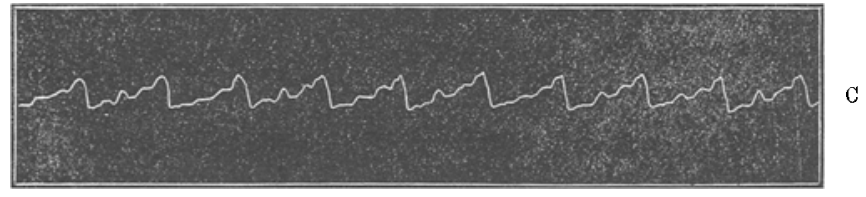

1) Ibidem 508 . 
Fälle und zwar habe ich sie neben anderen gewöbnlich alternirenden vor mehreren Wochen wiederholt auftreten sehen.

No. $38 \mathrm{~b}$.

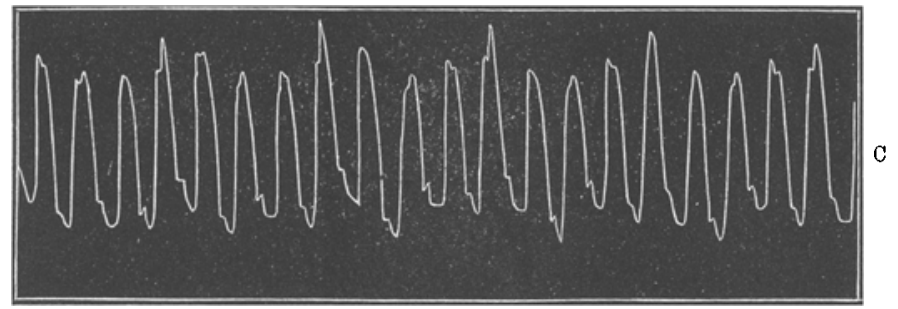

Die Herzcurve $58 \mathrm{~b}$ zeigt zur Genïge, worauf diese Erscheinung beruht; es verhalten sich die Contractionen des Herzens dabei bezüglich ibrer Intensität gleichsam wie in einer Verbindung der zu einem Pulsus myurus mit einem alternans gehörigen Herzthätigkeit bei einem entsprechenden Wechsel in der Zeitdauer der einzelnen Diastolen. $\mathrm{Ob}$ auf einer folgenden hohe und niedere Pulse jeweilig eine gleichgipflige oder gleichbasige Beschaffenheit haben, wird wohl im Ganzen davon abhängen, ob das Herz aus irgend welcher Ursache in der der ersten normaler Systole folgenden Diastole auf einer halben systolischen Contraction stehen bleibt oder aber in die volle Diastole übergehend nur einer zweiten schwächeren systolischen Contraction fähig wird. Von vornherein wäre vielleicht $\mathrm{zu}$ vermuthen, dass in den Fällen, in denen mechanische Fehler im Herzen gegeben sind (Mitralfehler) durch die mangelhafte Füllung des linken Ventrikels dieser selbst nicht in die volle Diastole tibergeht, und sich von Neuem contrahirt, während die vorherige Pulswelle noch nicht vollständig abgelaufen ist; unter solchen Verhältnissen miisste der zweite kleinere Puls im absteigenden Schenkel des vorherigen grösseren liegen, $d . h$. mehr minder gleichgipflig sein; dasselbe mitssen wir uns für die zweispitzigen Wellen der pbysiologischen Experimente vorstellen, indess dass hier ohne mechanische Herzfehler das Herz jedes zweite Mal aus anderen Ursachen nicht in die volle Diastole zurückkehrt. In den anderen Fällen vielleicht von fieberhafter oder sonstiger Schwäche des Körpers oder des Herzens (z. B. in den von Riegel und mir beobachteten) wurde das Herz zwar in die volle Diastole stets zurbickkehren, aber das zweite Mal sich schwächer contrahiren und hierdurch die in ihrer Höhe differenten Pulse als gleichbasige erscheinen.

Dass aber die eben gegebene Auseinandersetzung höchstens theoretisch berechtigt ist, dass mannigfache Combinationen möglich sind, das zeigen z. B. der zehnte und elfte Fall meiner Beobach- 
tungen, in welchen zum Schluss der Curven eine gleichbasige Alternirung im Anschluss an gleichgipflige bezw. umgekehrt im elften Falle erscheinen; das beweisen die mannigfachen Herzurven, die auch in Fällen von HerzNo. 59. fehlern in der oben genannten Beziehung alterniren. Um diesen Ueber-

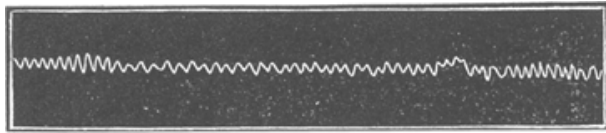
gang an Pulsen, die beispielsweise ron Mitralfehlern stammen, zu demonstriren, verweise ich auf die in Wolff's ') Lehrbuch uber den Arterienpuls gegebene Pulscurve No. 216. In derselben finden wir neben einem gleichgipfligen Pulsus trigeminus einen solchen mit gleichen Basen und ähnliches im Beginn des dritten Curvenschnittes der oberen Reibe in No. 221. Wurde dieses allein neben der von Traube und Riegel zugestandenen inneren grossen Verwandtschaft dieser beiden Pulsarten vielleicht schon genügen sie auch vollständig zu identificiren, so wird dies, wie ich glaube, zur Gewissheit nach folgenden von mir experimentell an Hunden gefundenen Curvenzeichnungen.

Die Curve No. 59, die vom rechten Ventrikel eines curarisirten Hundes, bei dem die Athmung suspendirt wurde, stammt, zeigt, wie bald die Curvengipfel, bald die Basen in gleicher Linie stehen, d. h. wie das Herz bald aus der halben Diastole in die nächste Systole, $\dot{\sim}$ bald aus der vollen Diastole in eine folgende schwächere Systole îberging. Exquisiter finden wir diese Uebergänge in einer von $\mathrm{Marey}^{2}$ ) bei Gelegenheit anderer Versuche gewonnenen und in seinem Werke veröffentlichten Curve, die ich hier zum Theil (No. 60) wiedergebe: es heisst bezüglich derselben in dem oben genannten Werke: „Il s'agit d'un coeur (de tortues) dont le sérum a été empoissonné par l'émétique ete." Hieraus war schon zu vermuthen, dass unter solchen Verhältnissen auch der Puls in der Arterie gleiche Uebergänge zeigen müsste und dass dem thatsüchlich so sei, ergab zufällig ein folgender Versuch: die nach-

1) 0. J. B. Wolff, Charakteristik des Arterienpulses. Leipzig. 1865. S. $123 \mathrm{ff}$.

2) Physiologie expérimentale. Travaux du laboratoire de M. Marey. II. 1876. Paris. p. 168. No. IV.

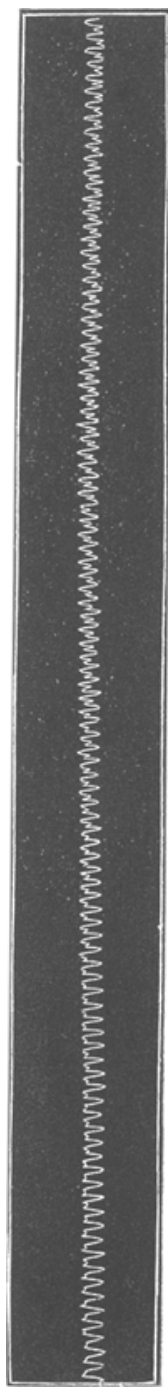

0 


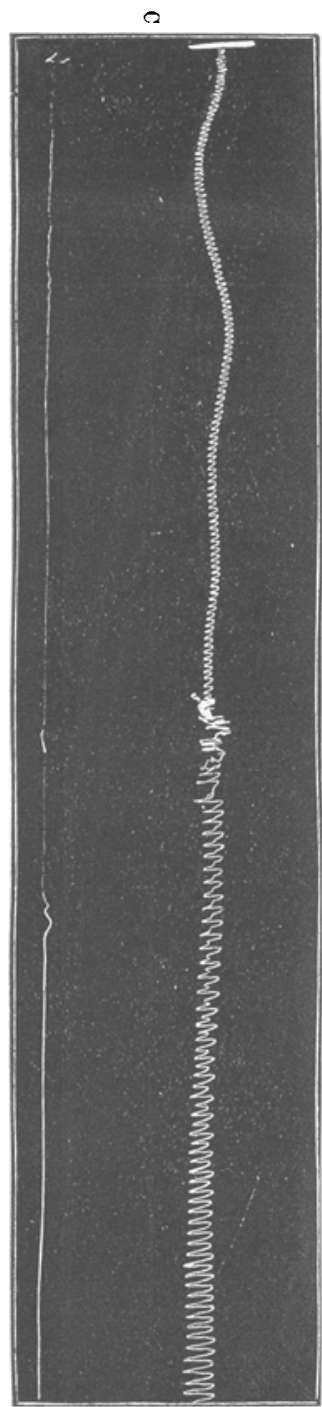

stehende Curve (No. 61) stammt aus der Carotis eines unter dieselben experimentellen Bedingungen wie zuror gebrachten Hundes; der erste Theil ist bei intacter, der zweite bei suspendirter ktinstlicher Athmung gewonnen. Sie demonstrirt auf das evidenteste die Richtigkeit meines bereits oben gegebenen Vergleiches des Pulsus alternans und bigeminus mit dem Pulsus dicrotus und capricans, d. h. des möglichen Ueberganges des einen in den anderen: die ersten fünf bis sechs Pulse des zweiten Abschnittes nämlich erscheinen als zweispitzige Wellen, als reiner Pulsus bigeminus, mit jedem folgenden sinkt der zweite kleinere immer deutlicher werdende Puls tiefer herab, um im achtzehnten und neunzehnten u. s. w. als reiner alternans sich zu präsentiren; von hier ab wächst derselbe als gleichbasiger immer höher, um schliesslich in den normalen iiberzugehen.

Ich glaube kaum, dass noch ein weiteres zur Erklärung dieser Curve hinzuzufügen wäre und dass sie allein schon hinreicht, um die volle Identität des Pulsus alternans und bigeminus zum mindesten als sehr wahrscheinlich erscheinen zu lassen. 